\title{
Oddness, modularity, and exhaustification
}

\author{
Guillermo Del Pinal
}

Forthcoming in Natural Language Semantics

\begin{abstract}
According to the 'grammatical account', scalar implicatures are triggered by a covert exhaustification operator present in logical form. This account covers considerable empirical ground, but there is a peculiar pattern that resists treatment given its usual implementation. The pattern centers on odd assertions like \#Most lions are mammals and \#Some Italians come from a beautiful country, which seem to trigger implicatures in contexts where the enriched readings conflict with information in the common ground. Magri $(2009,2011)$ argues that, to account for these cases, the basic grammatical approach has to be supplemented with the stipulations that exhaustification is obligatory and is based on formal computations which are blind to information in the common ground. In this paper, I argue that accounts of oddness should allow for the possibility of felicitous assertions that call for revision of the common ground, including explicit assertions of unusual beliefs such as Most but not all lions are mammals and Some but not all Italians come from Italy. To adequately cover these and similar cases, I propose that Magri's version of the Grammatical account should be refined with the novel hypothesis that exhaustification triggers a bifurcation between presupposed (the negated relevant alternatives) and at-issue (the prejacent) content. The explanation of the full oddness pattern, including cases of felicitous proposals to revise the common ground, follows from the interaction between presupposed and at-issue content with an independently motivated constraint on accommodation. Finally, I argue that treating the exhaustification operator as a presupposition trigger helps solve various independent puzzles faced by extant grammatical accounts, and motivates a substantial revision of standard accounts of the overt exhaustifier only.
\end{abstract}

Keywords scalar implicatures · exhaustification · oddness · presuppositions · accommodation $\cdot$ logical entailment $\cdot$ contextual entailment $\cdot$ pragmatics

Guillermo Del Pinal

University of Illinois Urbana-Champaign

E-mail: delpinal@illinois.edu 


\section{Introduction}

Scalar enrichments, such as the 'some but not all' reading of (1a), are a ubiquitous feature of ordinary discourse. The basic account of these kinds of enrichments is due to Grice $(1975,1989)$. Suppose that a cooperative speaker $S$ asserted $\phi_{\exists}$ in a context, such as (1), where its $\phi_{\forall}$-alternative is relevant. Since $\phi_{\forall}$ is more informative than $\phi_{\exists}$, we (the imagined addressees) can infer that $S$ was not in a position to assert $\phi_{\forall}$. Assuming $S$ is knowledgeable or opinionated, we can further infer that $S$ believes that $\phi_{\forall}$ is false. $^{1}$

\section{Context: Did Mary do any of the homework?}

a. Mary did some of the homework.

b. $\operatorname{Alt}\left(\phi_{\exists}\right)=\left\{\begin{array}{l}\phi_{\exists}=\text { Mary did some of the homework. } \\ \phi_{\forall}=\text { Mary did all of the homework. }\end{array}\right.$

c. $\quad$ Exh[Mary did some of the homework]

$\approx$ Mary did some of the homework $\wedge \neg$ Mary did all of the homework

According to the grammatical theory, scalar enrichments are the output of processes similar to the one just described, except that they are triggered by a covert exhaustification operator, Exh, which has a meaning akin to that of only, as illustrated in (1c). ${ }^{2}$ One advantage of the grammatical view is that-unlike its pragmatic counterpart - it immediately predicts that scalar enrichments can appear in embedded positions. This prediction is supported by examples like (2a) and (3a), since their most salient reading is the one captured by the corresponding parses with embedded Exh:

(2) a. Every student who did some of the homework got a cookie. But those who did all of it got a cake.

b. Every student $x$ Exh $[x$ did some of the homework] [x got a cookie]

a. Mary did two or six of the problems.

b. Exh[Mary did two of the problems] or she did six of the problems

Consider first (2a). While uses of some in the restrictor of a universal quantifier are not typically interpreted as 'some but not all', due to its continuation that is precisely the enrichment observed in (2a). Moving next to (3a), notice that, on its most salient reading, it is false in worlds in which Mary did exactly three, four, or five of the problems. That is precisely the reading we obtain if we exhaustify the first disjunct.

An important characteristic of examples like (1a)-(3a) is that Exh is introduced to increase discourse coherence: compared to their literal counterparts, the exhaustified readings make the target speaker come out as more rational and/or

\footnotetext{
1 For readability, I use symbols like ' $\phi$ ' to stand for both components of LFs and their interpretations. When this is potentially confusing, I use $\llbracket \phi \rrbracket$ to refer to the interpretation of $\phi$. Unless otherwise noted, I will assume that propositions are represented as sets of possible worlds, and that the common ground in a particular context $c$ is the set of possible worlds (or pairs of possible worlds and assignment functions) compatible with the information that is taken for granted by interlocutors for purposes of the conversation in $c$.

2 For an overview of the 'grammatical' account of scalar implicatures, see Chierchia et al. (2012). For an overview of a neo-Gricean approach, see Horn (2006). Recent empirical work on implicatures is summarized and discussed in Chemla and Singh (2014a,b).
} 
informative. Magri $(2009,2011,2017)$ argues that, to fully understand the computations triggered by exhaustification, we also have to explore whether enriched readings can systematically misfire. According to Magri, there is a class of examples, such as (4a)-(4b), in which automatically triggered scalar implicatures generate readings that conflict with the common ground, which explains their perceived oddness (even though the non-exhaustified interpretation is in each case compatible and informative given the common ground):

$$
\begin{aligned}
& \text { Common ground: normal (adult) background beliefs } \\
& \text { a. \#Mary is sometimes tall. } \\
& \text { b. \#Some Italians come from a beautiful country. }
\end{aligned}
$$

Intuitively, (4a) is odd because it conveys that Mary is sometimes but not always tall, yet we normally take for granted that height is a relatively stable property. Similarly, (4b) is odd because it conveys that some but not all Italians come from a beautiful country, yet we normally take for granted that co-nationals are from the same country. Magri argues that, while this intuitive analysis of oddness is approximately correct, implementing it requires making a series of theoretical stipulations that amount to doubling down on the grammaticalization of Exh. These are that (i) Exh is obligatory, (ii) the negated alternatives that are involved in the mismatch are necessarily relevant given the common ground, and (iii) Exh compares alternatives in terms of their logical but not their contextual strength. Finally, Magri proposes a general oddness filter which says, roughly, that an exhaustified expression is odd relative to a common ground $C$ whenever its content is inconsistent with $C$.

The goal of this paper is to defend a refined Magri-style account of oddness based on the existence of implicatures that mismatch with the common ground. The account I propose incorporates Magri's core theoretical innovations in (i)-(iii) according to which implicatures are generated by an obligatory exhaustification operator which excludes relevant alternatives based on a purely logical notion of entailment. As we will see in Sect. 2, grammatical (and neo-Gricean) accounts which reject any of (i)-(iii) under-generate oddness assignments in cases like (4a)(4b). However, I will argue that, in its current form, Magri's account over-generates oddness assignments. To see this, note that, when (exhaustified) assertions are inconsistent with the common ground, they tend to improve as a function of how explicit or at issue they render the part of their content which is inconsistent with the common ground. This is illustrated by patterns like (5a)-(5c):

$$
\begin{aligned}
& \text { Common ground: normal (adult) background beliefs } \\
& \text { a. \#Some Italians come from a beautiful country. } \\
& \text { b. ?Some but not all Italians come from a beautiful country. } \\
& \text { c. Some but not all Italians come from Italy. }
\end{aligned}
$$

From the listener's perspective, (5b) and (5c), unlike (5a), can be easily represented as calls to revise - rather than just add (potentially inconsistent) information tothe original common ground. Yet, as I argue in Sect. 3, if we assume that all expressions are exhaustified (even if the effect of exhaustification is sometimes vacuous), as we have to on Magri's account, and that all exhaustified expressions which are inconsistent with the common ground are marked as odd or infelicitous, then it is hard to explain these kinds of patterns. As a result, we seem to over-generate 
oddness assignments, from the listener's perspective, whenever a speaker calls for revision of what the listener takes to be in the common ground. In Sect. 4, I will argue that, to solve this problem, we need to introduce an important modification to Magri's version of the grammatical account of scalar implicatures, namely, Exh should be treated as a presupposition trigger. Specifically, readings enriched with scalar implicatures exhibit a bifurcation into presupposed (the negated relevant alternatives) and asserted/at-issue (the prejacent) content. Given this notion of presuppositional exhaustification, I will show that we can derive the target oddness patterns by appealing to a conservative extension of an independently motivated constraint on accommodation. I will also compare our target oddness cases with counterparts that involve overt exhaustification with only, and motivate a revision of the standard account according to which expressions of the form only $\phi$ presuppose $\phi$. In Sect. 5, I present independent evidence for the main innovations of my account. In Sect. 6 I return to the broader issue of why we need an account of oddness for cases like (4a)-(4b) that is based on implicatures that mismatch with the common ground. ${ }^{3}$

\section{Oddness and blind exhaustification}

This section presents Magri's (2009, 2011, 2017) grammatical theory of exhaustification, focusing on how it explains the oddness of cases like (4a)-(4b). ${ }^{4}$ Magri's theory modifies the standard grammatical view of both the formulation and distribution of Exh. On Magri's view, Exh should be formulated as in (6) and is obligatorily inserted at every proposition taking point. According to the definition of Exh in (6), the alternatives which are negated to generate enriched readings are those that are not strictly entailed by the prejacent, as captured in (6b), and that are 'relevant', in the sense of (6c), given the prejacent and common ground. Crucially, the notion of entailment used to define the set of excludable alternatives is an unambiguously logical notion: specifically, it is blind to the extralinguistic information of interlocutors; it 'sees' just the purely logical relations between the prejacent and its alternatives.

(6) Blind $\boldsymbol{E x h}$. Given $\phi$ and a set of excludable alternatives $\operatorname{Excl}(\phi), \operatorname{Exh}(\phi)$ expresses the conjunction of $\phi$ and the negation of each member of $\operatorname{Excl}(\phi)$ that is relevant in the context.

a. $\operatorname{Exh}(\phi)=\phi \wedge \wedge \neg \psi: \psi \in \operatorname{Excl}(\phi) \cap R$

b. $\operatorname{Excl}(\phi)$ is a subset of the set of formal/scalar alternatives of $\phi, \operatorname{Alt}(\phi)$, such that, for each $\psi \in A l t(\phi), \phi$ doesn't entail $\psi$ (or equivalently, such that $\psi$ can be negated consistently with $\phi$ ).

\footnotetext{
3 To be sure, there are various neo-Gricean-friendly accounts of oddness which do not appeal to the existence of implicatures/enriched readings that are inconsistent with the common ground. My main goal in this paper is not to directly argue against each of those neo-Gricean accounts (that is my focus in Del Pinal 2020), although I will discuss what I think is the most reasonable alternative account. My goal here is to defend a Magri-style account of oddness, based on implicatures/enriched readings which mismatch with the common ground, given a broadly grammatical approach to covert exhaustification.

4 For interesting refinements of the basic oddness patterns see also Magri (2014), PistoiaReda (2017), and Pistoia-Reda and Romoli (2017).
} 
c. $\quad R$ is a contextually assigned 'relevance' predicate which satisfies the following axioms: (i) the prejacent, $\phi$, is relevant, and (ii) if two propositions are contextually equivalent (in their local context), then they pattern together with respect to relevance.

The goal of Magri's grammatical theory is to allow for scalar enrichments that mismatch with the common ground, and thus help explain oddness patterns like (4a)-(4b), without negatively affecting the standard account of ordinary, informative uses of scalar enrichments. What we need to understand, then, is why a theory with that goal needs to assume both that Exh is obligatorily inserted/triggered at every proposition-taking site and that the notion of entailment used to define the set of excludable alternatives, Excl, is that of logical (not contextual) entailment, with the result that the effect of Exh can be trivialized only if there are either no excludable alternatives or if they are not necessarily relevant. ${ }^{5}$

To appreciate what is special about oddness cases like (4a)-(4b), it is best to start with a different kind of phenomenon, one in which we appeal to (embedded) Exh to explain why certain expressions are acceptable which would otherwise be infelicitous. Expressions like (7) are odd because they violate 'Hurford's Constraint' (HC), an oddness filter which says that a sentence which contains a disjunctive phrase of the form $S$ or $S^{\prime}$ is infelicitous if $S$ entails $S^{\prime}$ or $S^{\prime}$ entails $S$ :

$$
\text { \#Mary is from Paris or from France. }
$$

Interestingly, (8) below also seems to violate $\mathrm{HC}$, since the second disjunct, $\phi_{\forall}$, entails the first, $\phi_{\exists}$. If the only LF for (8) were the one that roughly corresponds to its surface form, as in (8a), then (8) would be incorrectly predicted to be odd. However, if Exh can occur in embedded positions, $\mathrm{LF}_{2}$ in $(8 \mathrm{~b})$ is also available. Importantly, $\mathrm{LF}_{2}$ does not violate $\mathrm{HC}$, since neither disjunct entails the other. Accordingly, (8b) is predicted to be the preferred LF for (8).

(8) Mary read some or all of the books.

$$
\begin{array}{ll}
\text { a. } & \mathrm{LF}_{1}: \phi_{\exists} \vee \phi_{\forall} \\
\text { b. } & \mathrm{LF}_{2}: \operatorname{Exh}\left(\phi_{\exists}\right) \vee \phi_{\forall}
\end{array}
$$

5 Some semanticists adopt a more complex formulation of 'excludable alternatives', Excl, than the one used in (6b) (see Sauerland 2004; Fox 2007; Chierchia et al. 2012). The revised formulation of Excl is presented in (i), where an alternative $\psi$ of $\phi$ is 'innocently excludable' $(I E)$ just in case (i) we can consistently negate $\psi$ while asserting $\phi$, and (ii) accepting both $\phi$ and $\neg \psi$ doesn't entail any other alternatives of $\phi$ (not already entailed by $\phi$ alone).

(i) a. $\operatorname{Excl}(\phi)$ is a subset of the set of formal/scalar alternatives of $\phi, A l t(\phi)$, such that, for each $\psi \in \operatorname{Alt}(\phi), \psi \in \operatorname{IE}(\phi, \operatorname{Alt}(\phi))$.

b. $\quad I E(\phi, \operatorname{Alt}(\phi))=\left\{\psi \in \operatorname{Alt}(\phi): \phi \nsubseteq \psi \wedge \neg \exists \psi^{\prime}\left[\psi^{\prime} \in \operatorname{Alt}(\phi) \wedge(\phi \wedge \neg \psi) \subseteq \psi^{\prime}\right]\right\}$

One motivation for this revision comes from cases in which each disjunct is a relevant alternative of disjunctions, which can create problems for the simpler formulation (but see Chierchia 2013). In this paper, we will not focus on those kinds of cases. What is important here is just that the version of Excl, defined in terms of 'innocent exclusion' $(I E)$ as in (ib), still uses the notion of logical entailment, and is extensionally equivalent to our simpler version in most of the cases we consider here. For these reasons, in this paper I use the simpler formulation of Excl in (6b) unless otherwise noted, with the understanding that the core results presented here still hold if we use the more complex $I E$ formulation of Excl instead. 
Exh is in this case introduced-i.e., a scalar implicature triggered - to 'save' an expression which would otherwise be marked as odd. This use of Exh can be implemented in a standard grammatical framework: given the two available LFs, disambiguation in favor of the non-odd one with embedded Exh is preferred. By interpreting an assertion of (8) via (8b) rather than (8a) we can represent the speaker as a cooperative conversational partner.

The suggestion that there are cases in which the presence of Exh generates oddness inverts the logic of 'rescuing' uses of Exh. Consider the oddness patterns in (9)-(10):

(9) Stable $C$ : Co-nationals come from the same country.

a. \#Some Italians come from a beautiful country.

b. (All) Italians come from a beautiful country.

(10) Ad hoc $C$ : Every year, Sue assigns the same grade to all her students.

a. \#This year, Sue assigned an A to some of her students.

b. This year, Sue assigned an A to all her students.

Why are (9a) and (10a) odd? Notice that, interpreted literally (based on their surface form and without covert exhaustification), not only are (9a) and (10a) compatible with their corresponding common ground, but both are actually informative (concerning Italy's beauty and Sue's specific grade assignments). Magri argues that (9a) and (10a) are odd because they trigger blind, mandatory scalar enrichments which clash with their corresponding common ground. Suppose that (9a) has the LF in (11a) and the alternatives in (11b). Since the logically stronger excludable alternative, $\phi_{\forall}$, is contextually equivalent, given $C$, to the prejacent, $\phi_{\exists}$, it is necessarily relevant and has to be negated, as captured in (11c). As a result, we get the enriched reading in (11d), which clashes with the stable common ground assumption that all Italians come from the same country.

$$
\begin{array}{ll}
\text { a. } & \mathrm{LF}_{1}: \operatorname{Exh}[\text { some Italians come from a beautiful country }]=\operatorname{Exh}\left(\phi_{\exists}\right) \\
\text { b. } & \operatorname{Alt}\left(\phi_{\exists}\right)=\left\{\begin{array}{l}
\phi_{\exists}=\text { some Italians come from a beautiful country } \\
\phi_{\forall}=\text { all Italians come from a beautiful country }
\end{array}\right. \\
\text { c. } & \phi_{\exists} \in R, \text { and since } \phi_{\exists} \cap C=\phi_{\forall} \cap C, \phi_{\forall} \in R \\
\text { d. } & \llbracket(11 \mathrm{a}) \rrbracket=\phi_{\exists} \wedge \neg \phi_{\forall}
\end{array}
$$

Analogous considerations explain the oddness of (10a), except that in this case the clash is with ad hoc information in the common ground, rather than with stable background beliefs. The stronger assertions of $(9 \mathrm{~b})$ and $(10 \mathrm{~b})$ are not predicted to be odd because, in each case, the prejacent is the logically strongest alternative. Since no alternative can be excluded, the resulting meaning is just the literal meaning, which is in each case compatible with the corresponding common ground.

Magri's account of oddness rests on two substantial stipulations concerning the distribution and types of computations triggered by Exh:

\section{Oddness based on mandatory, blind implicatures}

a. Exh is syntactically mandatory at matrix scope and any embedded propositional site.

b. Exh uses a strictly logical notion of entailment, i.e., one that is blind to entailments given the common ground. 
To see why (12a) is needed, suppose instead that Exh was optional. Then in cases when its presence generates oddness via a clash with the common ground that would otherwise be avoided, it should be dropped from the preferred parses. For example, given the common ground $C$ in (9), we would predict that, for (9a), an LF without $E x h$, as in (13a), would be preferred over the infelicitous one with $E x h$, in (11a). For unlike the interpretation in (11d), the one in (13b) doesn't clash with $C$ and is potentially informative (about Italy's beauty). So if Exh was optional, we would not be able to explain the oddness of (9a) via a clash with $C$, since the other (licensed) parse in (13a) is compatible and informative in $C$.

$$
\begin{array}{ll}
\text { a. } & \mathrm{LF}_{2}: \text { some Italians come from a beautiful country } \\
\text { b. } & \llbracket(13 \mathrm{a}) \rrbracket=\phi_{\exists}
\end{array}
$$

To see why assumption (12b) is needed, suppose Exh was not blind, specifically, that it only excludes those alternatives not entailed by the intersection of the prejacent and the common ground. Consider again $\mathrm{LF}_{1}$ in (11a) for Some Italians come from a beautiful country, in context $C$ in (9), and given the alternatives in (14a). Since (14b) obviously holds, the logically stronger alternative, $\phi_{\forall}$, would not be contextually excludable in $C$. As a result, the application of $E x h$, even if mandatory, would simply return the prejacent, $\phi_{\exists}$, which is compatible with $C$ and potentially informative.

$$
\begin{array}{ll}
\text { a. } & \operatorname{Alt}\left(\phi_{\exists}\right)=\left\{\begin{array}{l}
\phi_{\exists}=\text { some Italians come from a beautiful country } \\
\phi_{\forall}=\text { all Italians come from a beautiful country }
\end{array}\right. \\
\text { b. } & \phi_{\exists} \cap C \subseteq \phi_{\forall}
\end{array}
$$

We have just seen that the stipulations that Exh is mandatory, in the sense of (12a), and blind, in the sense of (12b), are required to explain the target oddness pattern via scalar enrichments which mismatch with the common ground. These stipulations move the grammatical theory of exhaustification even further away from its neo-Gricean roots and competitors. For blindness amounts to rejecting the view that Exh uses a notion of entailment that has access to any extralinguistic information, be it stable or ad hoc information. And holding that Exh is mandatory, even when it generates oddness, is in tension with approaches which conceive of implicatures as reducible to general/common sense reasoning procedures which aim to increase the informativeness or usefulness of assertions, relative to the common ground. ${ }^{6}$ From this perspective, Exh may be modeled as a covert version of the overt exhaustifier only, and we would thus expect that they generate similar oddness patterns in our target cases. According to Magri (2011), this is indeed what we observe, as captured in (15a)-(15b). This result in turn further supports the view that the oddness of (15a) is due to the presence of an obligatory and blind covert Exh operator.

$$
\text { Stable } C \text { : Co-nationals come from the same country. }
$$

a. \#Some Italians come from a beautiful country.

\footnotetext{
6 From a neo-Gricean perspective, the (potential) obligatoriness of Exh is hard to accept. For the point of triggering a scalar implicature, from a pragmatic perspective, is to make utterances more informative, or appropriate, given the common ground. This suggest that implicatures should not be triggered precisely when the resulting enriched reading clashes with the common ground while the unenriched ('literal') reading is at least consistent with it.
} 
b. \#Only some Italians come from a beautiful country.

c. $\operatorname{Only}\left(\phi_{\exists}\right) \approx \operatorname{Exh}\left(\phi_{\exists}\right)$

So far, we have assumed that an assertion is odd at a context of utterance if its exhaustified, enriched reading clashes with the common ground. This generalization seems roughly correct, but at this point we should explicitly formulate the filter which covers oddness patterns such as (9)-(10). Magri proposes the constraint on conversational dynamics in (16), basically a general oddness filter analogous to Hurford's Constraint (to cover oddness patterns with only, assume that in (16) Exh stands for both covert and overt exhaustification):

(16) Blind-mismatch hypothesis. If the blind strengthened meaning of $\phi$ is a contradiction relative to the common ground $C$, then $\phi$ is odd in $C$ : if $\operatorname{Exh}(\phi) \cap C=\emptyset$, then $\phi=\#$ in $C$

(Magri 2009, 2017)

Call Magri's account, which consists of blind Exh implemented as in (12), the parallel entry for the overt exhaustifier only, and the blind-mismatch hypothesis in (16), the 'blindness package'. The blindness package, we have seen, predicts the oddness patterns in (9)-(10). In Sects. 3-4, I extend and refine the target oddness pattern, argue that the blindness package has theoretical and empirical shortcomings, and present a revised version that can account for the full oddness pattern. ${ }^{7}$

7 If Exh is indeed obligatory, how can we explain the well-known phenomenon that, in standard cases, scalar implicatures are cancellable? For example, that John did some of the $H W$ triggers the usual 'not all' implicature in $C_{1}$ but not in $C_{2}$ :

(i) $\quad C_{1}$ : How much of the HW did John do?
a. John did some of the HW
$\rightsquigarrow \neg \phi_{\forall}$

(ii) $\quad C_{2}$ : Who did some of the $H W$ ?

a. John did some of the HW

$$
\varkappa_{\rightarrow} \neg \phi_{\forall}
$$

Magri appeals to Relevance (for a detailed defense, see Magri 2011). Suppose that (iiia) is obligatorily parsed as in (iiib). Consider the comprehensive set of alternatives in (iiic). Arguably, alternative-(iii) is irrelevant in $C_{1}$, while alternative-(ii) is irrelevant in $C_{2}$ (both suggestions are compatible with the minimal conditions on relevance specified in (6c) above).

(iii) a. John did some of the HW

b. LF: $\operatorname{Exh}[$ John did some of the HW]

c. $\quad A l t($ John some HW $)=\left\{\begin{array}{l}\text { (i) John did some HW } \\ \text { (ii) John did all HW } \\ \text { (iii) Peter did some HW } \\ \ldots\end{array}\right.$

As a result, the output of Exh[John did some of the $H W]$ is different in each context, as captured in (iva)-(ivb), with the result that the 'not all' implicature is observed only in $C_{1}$ :

(iv) a. In $C_{1}, E x h[$ John did some] $=$ John did some $\mathrm{HW} \wedge \neg$ John did all HW

b. In $C_{2} E x h[$ John did some] $=$ John did some HW $\wedge \neg$ Peter did some HW 


\section{Problems with the blindness package}

Magri's blindness package provides a promising account of the target oddness patterns. Yet as currently formulated, it has serious descriptive and explanatory shortcomings. Specifically, it over-generates oddness predictions, and for a simple theoretical reason. The root of the problem is that, in many cases, mismatches between assertions and the common ground do not generate oddness (from the listener's perspective). The blindness package, recall, rests on the assumption that, at LF, Exh is obligatorily attached to propositional clauses: if every assertion is exhaustified - even if the effect is trivial or vacuous - then, a fortiori, every assertion which is inconsistent with the common ground is also exhaustified. Surely, however, speakers often make acceptable assertions that aim to revise - rather than to just add information that is consistent with - the common ground. That is, they can make acceptable assertions that call for revision of what they believe other interlocutors believe is in the common ground. As formulated, the blind-mismatch hypothesis would filter out many of these quotidian conversational moves.

To begin to illustrate the problem, consider the oddness pattern in (17), starting with (17a), which is a somewhat simplified example of Magri-style oddness. Note that as the part of the content which conflicts with the common ground is made explicit ('at issue'), as in (17b) and (17d), the oddness of the corresponding expression markedly decreases. Indeed, (17b) and (17c), unlike (17a), seem to be fully acceptable ways of calling for revision of the common ground, even though most interlocutors would still hold that they are false and can refuse to update the (partially revised) common ground with their content. This difference between (17a) and (17b)-(17c) is brought out by the clear contrast, illustrated in (17d)-(17f), in the kinds of continuations that each statement felicitously admits.

\section{$C$ : normal information about the world}

a. \#Some lions are mammals.

b. Some lions are robots.

c. Some but not all lions are mammals.

d. \#Look, some lions are mammals. \#I know you think that is crazy, but ...

e. Look, some lions are robots. I know you'll think that is crazy but ...

f. Look, some but not all lions are mammals. I know you think that is crazy, but ...

Why are patterns like (17) problematic for the blindness package? Given just its unenriched reading, (17a) does not conflict with the common ground $C$. But its enriched reading includes the negation of its (relevant) scalar alternative, $\neg$ All lions are mammals, which is inconsistent with $C$. Due to this mismatch, the blindness package correctly predicts that (17a) is odd given $C$. So far, so good. Consider next (17b). In this case, the negation of its excludable alternative, $\neg$ All lions are robots, does not conflict with $C$. Still, since the exhaustified reading of (17b) entails the prejacent, Some lions are robots, which does conflict with $C$, we incorrectly predict that (17b) should also be odd. ${ }^{8}$ Finally, although matrix exhaustification in the case of $(17 \mathrm{c})$ is vacuous, the resulting reading (which is equivalent to the 'some but

8 This incorrect prediction holds for $(17 \mathrm{~b})$ even if the negation of the $\forall$-alternative is not added to its enriched reading (say, because the $\forall$-alternative is ignored or taken as non- 
not all' prejacent), conflicts with $C$, hence is also incorrectly predicted to be as odd, relative to $C$, as (17a). The problem, then, is that since the obligatorily exhaustified readings of $(17 \mathrm{a}),(17 \mathrm{~b})$, and $(17 \mathrm{c})$ all conflict with $C$, they are predicted to be uniformly odd by Magri's blind-mismatch hypothesis in (16). However, (17b) and (17c), even if taken as obviously false, are clearly less odd than (17a). ${ }^{9}$

Consider next the oddness pattern in (18), which starts with (18a), a standard example of Magri-style oddness. The key observation parallels the one made for the pattern in (17), namely, that as the part of the content which conflicts with the common ground $C$ is made more explicit ('at issue'), as in (18b)-(18c), the oddness of the corresponding expression markedly decreases. When trying to account for this contrast, the blindness package faces the same problem as before. Since (18a)(18c) all have exhaustified readings that are inconsistent with the common ground (even if exhaustification is vacuous in the case of (18b)-(18c)), the blindness package predicts that they should all pattern together in terms of acceptability and be uniformly classified as odd. Yet although (18a) is odd in $C,(18 \mathrm{~b})-(18 \mathrm{c})$ are clearly much better. Indeed, (18c) seems like a perfectly appropriate choice for a speaker who wants to call for revision of the common ground.

$$
\begin{aligned}
& \text { C: Co-nationals come from the same country. } \\
& \text { a. \#Some Italians come from a beautiful country. } \\
& \text { b. Some but not all Italians come from a beautiful country. } \\
& \text { c. Some but not all Italians come from Italy. }
\end{aligned}
$$

relevant). For since (17b) conflicts with $C$ even when its exhaustification is vacuous, the mismatch hypothesis in (16) incorrectly predicts that, given $C$, it should be as odd as (17a).

9 Simplified cases of oddness like (17a) are subtly different from standard Magri-style cases, repeated in (18a), (20a), and (21a) below. This is because, given normal (shared) background beliefs, (17a) is intuitively redundant, which could affect its acceptability, whereas the main predications in cases like (18a), (20a), and (21a) are modeled so as to convey new information relative to their corresponding common ground. Accordingly, examples like (17a) should not be used to motivate an account of oddness based on mismatching implicatures, although it is also not a problem for that account - assuming it is motivated by standard Magri-style examplesif oddness is in this specific case over-determined. Still, I begin with simpler examples like (17a) because, when compared with the variations in (17b) and (17c), they shed light on more complex oddness cases like (18a), (20a), and (21a) and on the problem of over-generation of oddness that their corresponding variations pose for Magri's blindness package. Having said that, it is arguable that the degree of oddness exhibited by (17a) can't be fully explained by appealing to its redundancy; for in that case, expressions like Lions are mammals and All lions are mammals should be equally odd, relative to normal shared beliefs. Yet although the generic and universally quantified variants are also usually uninformative, (17a) is substantially more degraded (for discussions of the specific conditions under which redundancy results in oddness see Mayr and Romoli 2016 and Sudo 2018). A reviewer notes that the generic might be preferred over the quantified variants because it arguably is (i) contextually equivalent and (ii) has stronger presuppositions, hence a principle along the lines of 'Maximize presuppositions' might entail that choosing a quantified over a generic alternative should lead to oddness. Whether (i)-(ii) hold depends on the specific account of the generic operator. Yet even if this suggestion works in this specific case, it would predict that the 'some' and 'all' sentences in all the Magri-style oddness patterns in which the generic version is also licensed should be equally degraded. As the reader can test by starting with cases like (18a), this generalization doesn't seem correct; and as we will see in Sect. 6, the cases in which it does can be explained by a revised version of the blindness package combined with independent principles concerning good questions and answers. Finally, some standard examples of Magri-style oddness, such as (20a) (see also (81)), do not plausibly have a generic reading (e.g., in (20a), Sue's assigning an A to some of her students is a one-time event, which doesn't have a generic/dispositional/habitual reading), hence also fall outside the scope of this competing account of oddness. 
One might worry that the oddness patterns in (17) and (18) are affected by the following potential confound: for some reason (and despite the set-up), listeners tend to evaluate (17b)-(17c) and (18b)-(18c) against a shifted common ground with which they are actually consistent (say, a science fiction scenario). Let us try to explicitly control for this and test if we still obtain the same kind of oddness pattern. Consider the oddness pattern in (19) below. The set-up here is this: assuming normal background information, the speaker $S$ objects to some arbitrary theory or argument because it has entailments that conflict with epistemically secure components of the common ground that, from $S$ 's perspective, his interlocutors wouldn't want to give up or revise. As before, the variants that felicitously and effectively call for such revision (a move that in this case $S$ is rejecting as part of his argumentative/rhetorical strategy) are (19c)-(19f), whereas (19a)-(19b) are still odd. In this case, the speaker $S$ clearly conveys to the interlocutors that he is using/assuming a normal common ground $C$; yet since (19c)-(19f) all have exhaustified readings which conflict with $C$, the blindness package incorrectly predicts that they should be as odd as (19a)-(19b). ${ }^{10}$

$$
\begin{aligned}
& C: \text { normal information about the natural and social world } \\
& S: \text { Your theory/argument must be wrong because it entails that... } \\
& \text { a. \#some lions are mammals. } \\
& \text { b. \#some Italians come from a beautiful country. } \\
& \text { c. some lions are robots. } \\
& \text { d. some but not all lions are mammals. } \\
& \text { e. some but not all Italians come from a beautiful country. } \\
& \text { f. some but not all Italians come from Italy. }
\end{aligned}
$$

In light of the observations thus far, let us re-examine whether covert Exh and only really generate parallel oddness patterns in matching contexts. Most proponents of the grammatical view assume that Exh and only have parallel semantics, modulo the possibility that only presupposes, rather than asserts, its prejacent. Whenever the presupposition of only is entailed by the common ground, that difference should not matter to application of the blind-mismatch hypothesis, which thus predicts that they pattern together. Indeed, according to Magri (2011), Exh and only generate similar oddness patterns. Consider the examples in (20), however. I submit that, compared to (20a), (20b) is not only less odd, but is more effective as a way to call for revision of the common ground. In this respect, (20b) is closer to the 'some but not all' variant in (20c) than to (20a). These judgments concerning (20a)-(20c) are supported by the corresponding contrasts in the continuations they license, captured in (20d)-(20f).

(20) Ad hoc C: Every year, Sue assigns the same grade to all her students

a. \#This year, Sue assigned an A to some of her students.

b. ?This year, Sue assigned an A to only some of her students.

c. This year, Sue assigned an A to some but not all of her students.

d. \#Yet this year, Sue assigned an A to some of her students. \#It was a peculiar year.

\footnotetext{
10 I'm grateful to an anonymous reviewer for discussion of this issue and for suggesting the use of examples like those in (19).
} 
e. Yet this year, Sue assigned an A to only some of her students. It was a peculiar year.

f. Yet this year, Sue assigned an A to some but not all of her students. It was a peculiar year.

The same kind of oddness pattern, pointing to an interesting difference between Exh and only, is captured in (21). Again, it seems clear that (21b) is markedly less odd than (21a), and in particular can support a call for radical revision of the common ground, as illustrated in $(21 \mathrm{e})$, even if interlocutors reject the full subsequent update. In addition, although the proposition that Mary is sometimes but not always tall conflicts with background beliefs about the world, explicitly asserting that content does not seem to lead to oddness, as shown in (21c), and also supports calls for revising the common ground, as shown in (21f). As currently stated, however, the blindness package incorrectly predicts that assertions of sentences of the form $\operatorname{Exh}\left(\phi_{\exists}\right), \operatorname{Only}\left(\phi_{\exists}\right)$, and $\phi_{\exists \wedge \neg \forall}$ in cases like (20) and (21) should pattern together and be uniformly marked as odd.

$C$ : normal information about the world, incl. that height is a stable property

a. \#Mary is sometimes tall.

b. ?Mary is only sometimes tall.

c. ?Mary is sometimes but not always tall.

d. \#Mary is sometimes tall. \#She is so strange!

e. Mary is only sometimes tall. She is so strange!

f. Mary is sometimes but not always tall. She is so strange!

At this point, taking a more abstract perspective will help sharpen the challenge which these kinds of patterns present to Magri's original blindness package. ${ }^{11}$ As Stalnaker $(1978,2014)$ points out, any principle of rational communication can be used by a listener in at least three ways: to interpret what is said, as a clue to what is actually presupposed/in the common ground, or as a basis for evaluating the action of a speaker. Consider one such principle, specially relevant for us (since the blind-mismatch hypothesis in (16) is arguably based on it):

(22) Informativity. Asserted propositions should be true in some but not all of the worlds in the common ground - i.e., assertions should be informative without collapsing the common ground (cf. Stalnaker 1978).

Let us model our target examples in terms of a listener $L$, a context set $C_{L}(=$ the common ground according to $L$ ), a speaker $S$, and a context set $C_{S}$ (= the common ground according to $S$ ). If $L$ is certain that $C_{L}$ captures the common ground (i.e., that $C_{L}=C_{S}$ ) and that $S$ asserted $\phi$ such that $\phi \cap C_{L}=\emptyset$, then $L$ can conclude that $S$ violated Informativity. In most actual situations, however, $L$ should be modeled as treating $C_{L}$ as a defeasible hypothesis (with varying degrees of confidence). Crucially, whenever $C_{L}$ is defeasible, apparent violations of Informativity by $S$ - such as that $S$ asserted $\phi$ and $C_{L} \cap \phi=\emptyset$ - can be used by $L$ as evidence that $C_{L}$ should be revised. This is why speakers can (sometimes) use assertions which conflict with $C_{L}$ and thereby signal to $L$ that $C_{L}$ should be

\footnotetext{
11 The following discussion was greatly aided by conversations with Itai Bassi, Gennaro Chierchia, Jacopo Romoli, and Uli Sauerland.
} 
revised. From this perspective, the patterns above can be described as follows: while the 'only' $\left(=\operatorname{Only}\left(\phi_{\exists}\right)\right)$ and 'some but not all' $\left(=\phi_{\exists \wedge \neg \forall}\right)$ assertions are adequate ways for $S$ to signal to $L$ that $C_{L} \neq C_{S}$, their Exh-based counterparts $\left(=\operatorname{Exh}\left(\phi_{\exists}\right)\right)$ do not seem to succeed, in general, in conveying that kind of evidence.

The challenge, then, is that it is hard to explain that difference on Magri's version of the blindness package. For this account entails, for patterns like those in (20) and (21), the following result: given the initial context $C_{L}$, the assertions of $\operatorname{Exh}\left(\phi_{\exists}\right), \operatorname{Only}\left(\phi_{\exists}\right)$, and $\phi_{\exists \wedge \neg \forall}$ express the same content, from the perspective of $L$, and that content conflicts with $C_{L}$. If we hold that the $\operatorname{Exh}\left(\phi_{\exists}\right)$ assertion is resiliently odd for $L$ because, for some reason, $L$ refuses to revise $C_{L}$ and thereby models that assertion as a violation of basic principles of rational communication, then we seem to be committed to the same story for the $O n l y\left(\phi_{\exists}\right)$ and $\phi_{\exists \wedge \neg \forall}$ assertions, thereby over-generating predictions of oddness. If, on the other hand, we say that $L$ can revise $C_{L}$ by using its conflict with the $O n l y\left(\phi_{\exists}\right)$ or the $\phi_{\exists \wedge \neg \forall}$ assertions as evidence against the hypothesis that $C_{L}=C_{S}$, then we seem to be committed to the same story for the $\operatorname{Exh}\left(\phi_{\exists}\right)$ case, thereby loosing the original explanation of oddness. Either way, we fail to capture the key distinction, namely, that just the Only $\left(\phi_{\exists}\right)$ and $\phi_{\exists \wedge \neg \forall}$ assertions can be used felicitously in a way that reliably leads to revision of the common ground. This suggests that Magri's blindness package needs to be modified-specifically, to (help) explain why assertions of expressions that have the same entailments, relative to a hypothesized context $C_{L}$, can have such different effects on what listeners do with $C_{L} \cdot{ }^{12}$

Summing up, the oddness patterns in (18)-(21) support a simple observation with significant theoretical reach. Interlocutors often use assertions to call for radical revision - and not just the addition of information to - the common ground. The blindness package should be revised so that it doesn't systematically over-

12 This is not to suggest, of course, that the $\phi_{\exists \wedge \neg \forall}$ and $O n l y\left(\phi_{\exists}\right)$ assertions always succeed in making $L$, the listener, revise $C_{L}$. In particular, if $S$, the speaker, has just made it very clear (e.g., via an explicit assertion), that he accepts the part of $C_{L}$ which causes the conflict with $S$ 's subsequent assertion, revision of $C_{L}$ will probably not take place, and the infelicity or oddness of the assertion markedly increases. Many examples of incoherent sequential assertions, such as (ia)-(ib), are of this kind. At the same time, when there is even a small opening to revise the default interpretation of the first assertion so as to make it coherent with the subsequent assertion, we can observe, again, that $\operatorname{Only}\left(\phi_{\exists}\right)$ and $\phi_{\exists \wedge \neg \forall}$ assertions are much more effective than their $\operatorname{Exh}\left(\phi_{\exists}\right)$ counterpart, as illustrated by the contrast between (iia) and (iib)-(iic) (this holds even though the use of 'yet' suggests to $L$ that some kind of revision/caveat is about to follow):

(i) al lions belong to the same natural kind. And \#only some/\#some but not all of them are mammals.

b. All Italians come from the same county and \#only some/\#some but not all of them come from a beautiful country.

(ii) a. Every year, every professor in this school assigns the same grade to each of their students. \#Yet this year Sue, who is a prof in this school, assigned an A to some of her students.

b. Every year, every professor in this school assigns the same grade to each of their students. Yet this year Sue, who is a prof in this school, assigned an A to only some of her students.

c. Every year, every professor in this school assigns the same grade to each of their students. Yet this year Sue, who is a prof in this school, assigned an A to some but not all of her students. 
generate oddness predictions across all of these common conversational moves. These patterns also highlight a ground level observation that should play a central role in any revision of the blindness package: compared to only and 'some but not all' variants, Exh does not seem to achieve the same level of explicitness in highlighting or making at issue information that is potentially inconsistent with the common ground. Let us call the oddness pattern captured in (18)-(21) the 'full oddness pattern'.

\section{The revised blindness package}

In this section, I present a novel version of the blindness package that can explain the full oddness pattern, and which offers various additional empirical advantages. I present this account in two steps, the goal being to reveal the descriptive and theoretical rationale for the final formulation. Despite substantial modifications, the final formulation preserves the basic pillars of Magri's original blindness package, namely, that exhaustification is obligatory and uses a purely logical notion of entailment that is blind to information in the common ground.

\subsection{First attempt}

Given the empirical challenge raised in Sect. 3, it is natural to begin by trying to constrain the blind-mismatch hypothesis in some principled way. To formulate oddness filters, I will adopt some standard conventions from dynamic semantics. $C[q]$ stands for the update of the common ground $C$ with proposition $q$, where both can be represented as sets of possible worlds. When relevant, propositions are represented as $p p^{\prime}$, where the underlined part stands for the presupposition and the non-underlined primed part for the assertive/at-issue component. Using this terminology, an initial revision of the original blind-mismatch hypothesis is presented in (23):

(23) Presuppositional mismatch hypothesis (preliminary). If $\phi\left(=p p^{\prime}\right)$ has a presupposition which collapses the common ground $C$, then asserting $\phi$ in $C$ is odd:

$$
C\left[\underline{p} p^{\prime}\right]=\# \text { if } C[\underline{p}]=\emptyset
$$

This oddness filter arguably follows from general constraints on conversational dynamics. One important general principle, due to Stalnaker (1978), is that the presuppositions of assertions should be entailed by the common ground:

$$
C\left[\underline{p} p^{\prime}\right]=\# \text { unless } C \neq \# \text { and } C \models \underline{p}
$$

In practice, the effect of this principle is modulated by the widespread use of accommodation (Lewis 1979). Yet accommodation is also constrained: typically, it is licensed when the common ground is at least consistent with the presupposition of an assertion, but not when the common ground is strictly inconsistent with it (Heim 1992, Stalnaker 1998, von Fintel 2008). From this perspective, the mismatch 
hypothesis in (23) is a limiting case of the presupposition oddness filter, namely, a case when (global) accommodation is blocked..$^{13}$

The next step is to revisit the entries for Exh and only. Given the presuppositional mismatch hypothesis ('ps-mismatch hypothesis') and the results from Sect. 3, one natural thought would be to modify our assumptions about what is presupposed vs. asserted in the entries for Exh and only. As a first attempt, let us assume that while only presupposes its prejacent and asserts the negation of its excludable alternatives (as is standardly assumed), Exh has a complementary presuppositional vs. at-issue structure: ${ }^{14}$

(25) Blind presuppositional $\boldsymbol{E x h}^{p}$. Given $\phi$ and a set of excludable alternatives $\operatorname{Excl}(\phi), \operatorname{Exh}^{p}(\phi)$ presupposes the negation of each (relevant) member of $\operatorname{Excl}(\phi)$ and asserts $\phi$ :

$$
\text { a. } \operatorname{Exh}^{p}(\phi)=\left\{\begin{array}{l}
\text { ps: } \bigwedge \neg \psi: \psi \in \operatorname{Excl}(\phi) \cap R \\
\text { at-issue: } \phi
\end{array}\right.
$$

(26) Blind presuppositional only. Given $\phi$ and a set of excludable alternatives $\operatorname{Excl}(\phi), \operatorname{Only}(\phi)$ presupposes $\phi$ and asserts the negation of each (relevant) member of $\operatorname{Excl}(\phi)$ :

a. $\operatorname{Only}(\phi)=\left\{\begin{array}{l}\text { ps: } \phi \\ \text { at-issue: } \bigwedge \neg \psi: \psi \in \operatorname{Excl}(\phi) \cap R\end{array}\right.$

From here on, I use ' $E x h^{p}$ ' to refer to the presuppositional exhaustification operator, and ' $E x h$ ' for the standard, flat exhaustification operator. As formulated, the source for the structuring of presupposed vs. assertive/at-issue content of $E x h^{p}$ and only is deliberately left open (if one opts for a semantic construal, these structures are rigid; if one goes for a more pragmatic one, they are more like defaults). The net effect of these revisions is the following. Given the ps-mismatch hypothesis in (23), covert Exh generates oddness when an excluded alternative is inconsistent with the common ground, whereas only generates oddness when the prejacent is inconsistent with the common ground. This revised blindness package makes room for assertions that call for revision of the common ground. Crucially, however, content that calls for radical belief revision should (in general) be explicit/at-issue.

To determine if this revised blindness package predicts the full oddness pattern, consider first the simple pattern in (17), the core part of which is repeated in (27) and (28). In the case of (27a), the presupposition that not all lions are mammals, derived as in (27b)-(27e), is inconsistent with the common ground. As a result, we correctly predict that $(27 \mathrm{a})$ is odd. In the case of $(28 \mathrm{a})$, the presupposition that not all lions are robots is compatible with (indeed entailed by) the common ground. Although its at-issue content is inconsistent with the common ground, this doesn't result in oddness according to our new ps-mismatch hypothesis (again,

\footnotetext{
13 Heim (1992, p.212): "Assumptions to be accommodated are supposed to be uncontroversial and unsurprising. One may explicitly assert controversial and surprising things (in fact one should) but to expect one's audience to accept them by way of accommodation is not good conversational practice."

14 Some proponents of the grammatical approach might want to refine these entries to ensure that while covert exhaustification may be vacuous (which would be especially attractive for those who stipulate that it is obligatory, but see Chierchia 2013), overt exhaustification with only is infelicitous if no alternatives can be excluded.
} 
interlocutors can either reject the at-issue content or revise the common ground). This is the correct prediction for $(28 \mathrm{a})$.

\section{$C$ : normal background information}

a. \#Some lions are mammals.

b. LF: $\operatorname{Exh}^{p}$ [some lions are mammals]

c. $\operatorname{Alt}\left(\phi_{\exists}\right)=\left\{\begin{array}{l}\phi_{\exists}=\text { some lions are mammals } \\ \phi_{\forall}=\text { all lions are mammals }\end{array}\right.$

d. $\quad \phi_{\exists} \in R \wedge \phi_{\exists} \cap C=\phi_{\forall} \cap C \Rightarrow \phi_{\forall} \in R$

e. $\llbracket(27 \mathrm{~b}) \rrbracket=\left\{\begin{array}{l}\text { ps: } \neg \text { all lions are mammals } \\ \text { at-issue: some lions are mammals }\end{array}\right.$

(28) C: normal background information

a. Some lions are robots.

b. LF: $\operatorname{Exh}^{p}[$ some lions are robots]

c. $\operatorname{Alt}\left(\phi_{\exists}\right)=\left\{\begin{array}{l}\phi_{\exists}=\text { some lions are robots } \\ \phi_{\exists}=\text { all lions are robots }\end{array}\right.$

d. $\quad \phi_{\exists} \in R \wedge \phi_{\exists} \cap C=\phi_{\forall} \cap C \Rightarrow \phi_{\forall} \in R$

e. $\llbracket(28 \mathrm{~b}) \rrbracket=\left\{\begin{array}{l}\text { ps: } \neg \text { all lions are robots } \\ \text { at-issue: some lions are robots }\end{array}\right.$

So far, the revised blindness package improves on the original version. Consider next the oddness pattern in (20). Recall that the sentences with overt only feel less odd than the ones with covert exhaustification, and more reliably support calls for belief revision. Unfortunately, this contrast between $E x h^{p}$ and only is not predicted by our (first) revised account. To see this, focus on (20a), repeated below in (29a), and (20b), repeated in (30a). On this revised account, (29a) presupposes that Sue did not assign an A to all her students, as shown in (29e). This presupposition is compatible with the ad hoc common ground $C$, and when combined with it, entails that no student got an A. This update of the ad hoc $C$, in turn, clashes with the at-issue content of the assertion, namely, that some students got an A. Still, the latter kind of clash is not filtered out by the ps-mismatch hypothesis: as formulated in (23), this principle just filters out direct inconsistencies between presuppositions and the common ground. As a result, we incorrectly predict that (29a), given the ad hoc $C$, is felicitous.

(29) Ad hoc C: Every year, Sue assigns the same grade to all her students.

a. \#This year, Sue assigned an A to some of her students.

b. LF: $\operatorname{Exh}^{p}$ [Sue assigned an A to some students] $=\operatorname{Exh}^{p}\left(\phi_{\exists}\right)$

c. $\operatorname{Alt}\left(\phi_{\exists}\right)=\left\{\begin{array}{l}\phi_{\exists}=\text { Sue assigned an A to some students } \\ \phi_{\forall}=\text { Sue assigned an A to all students }\end{array}\right.$

d. $\quad \phi_{\exists} \in R \wedge \phi_{\exists} \cap C=\phi_{\forall} \cap C \Rightarrow \phi_{\forall} \in R$

e. $\quad \llbracket(29 b) \rrbracket=\left\{\begin{array}{l}\text { ps: } \neg \text { Sue assigned an A to all students } \\ \text { at-issue: Sue assigned an A to some students }\end{array}\right.$

This revised account also predicts that (30a) should not be odd. (30a) presupposes that Sue assigned an A to some of her students, which is consistent with the ad hoc $C$. When this presupposition is added to $C$, we get the entailment that Sue assigned an A to all her students, which does clash with the at-issue content of the assertion. As before, the ps-mismatch hypothesis doesn't filter out this kind of 
move; i.e., it does not filter out clashes between the common ground (even after accommodation) and the at-issue content of assertions. ${ }^{15}$ In this case, however, the no-oddness prediction is correct.

(30) Ad hoc $C$ : Every year, Sue assigns the same grade to all her students.

a. This year, Sue assigned an A to only some of her students.

b. LF: Only[Sue assigned an A to some students] $\quad=\operatorname{Only}\left(\phi_{\exists}\right)$

c. $\operatorname{Alt}\left(\phi_{\exists}\right)=\left\{\begin{array}{l}\phi_{\exists}=\text { Sue assigned an A to some students } \\ \phi_{\forall}=\text { Sue assigned an A to all students }\end{array}\right.$

d. $\llbracket(30 \mathrm{~b}) \rrbracket=\left\{\begin{array}{l}\text { ps: Sue assigned an A to some students } \\ \text { at-issue: } \neg \text { Sue assigned an A to all students }\end{array}\right.$

Summing up, the revised blindness package in (23)-(26) makes the correct predictions for simple oddness patterns such as those in (17). The reason is this: the assertions that generate oddness in these cases all presuppose information that is inconsistent with the common ground, and is thus hard to accommodate. Unfortunately, more complex patterns such as those in (20) undermine this account. In cases like $(20 \mathrm{a}) /(29 \mathrm{a})$, the exhaustified expressions presuppose information that is, although not entailed, at least consistent with the ad hoc common ground, but which when conservatively accommodated is inconsistent relative to the at-issue content of the assertion. This kind of conversational move is clearly strange, yet our current formulation of the ps-mismatch hypothesis doesn't rule it out. In addition, if this sort of conversational move is filtered out as odd, the observation that cases like (30a) are not odd suggests that only triggers a weaker presupposition than assumed in standard entries such as (26).

\subsection{Second attempt}

In light of the shortcomings of the first revision of the blindness package, consider the stronger version of the ps-mismatch hypothesis in (31). This oddness filter, it seems to me, still follows from relatively uncontroversial principles of conversational dynamics. As before, it filters out assertions which presuppose information that is inconsistent with the common ground. However, it also filters out conversational moves that, given the common ground $C$, lead to the following problematic kind of update: although neither the presupposition nor the at-issue content of the assertion are on their own inconsistent with $C$, the assertion has a presupposition that, when conservatively accommodated in $C$, results in an information state that is inconsistent with its at-issue content. ${ }^{16}$

\footnotetext{
15 To be clear, this is not to say that any assertion whose at-issue content clashes with the common ground is felicitous so long as its presuppositions are consistent with the common ground. This depends, i.a., on whether one can figure out how to accommodate the target information (see von Fintel 2008), and whether the assertion can be construed as a coherent call for revision of the common ground, given such information as what the speaker has previously asserted. This presumably rules out as infelicitous sequences in which a speaker generates a series of assertions whose at-issue contents are inconsistent (see footnote 12).

16 This revised ps-mismatch hypothesis is intended as an implementation of the Lewis/Heim/von Fintel insight about constraints on what can be accommodated, which says roughly that you can introduce controversial information into conversations, but such information should in general be fully contained in the assertive part of your assertions. Independent evidence for both components of the ps-mismatch hypothesis is reviewed in Sect. 5.1.
} 
(31) Presuppositional mismatch hypothesis (revised). If $\phi\left(=p p^{\prime}\right)$ has a presupposition which is inconsistent with the common ground $C$, then $\phi$ is odd in $C$. In addition, if $\phi$ has a presupposition and assertive content which are each consistent with $C$, but the update of $C$ with the presupposition is inconsistent with the assertive content of $\phi$, then $\phi$ is odd in $C$ :

$$
C\left[\underline{p} p^{\prime}\right]=\# \text { if }\left\{\begin{array}{l}
C[\underline{p}]=\emptyset \text {, or } \\
C[\underline{p}] \neq \emptyset \& C\left[p^{\prime}\right] \neq \emptyset \& C[\underline{p}]\left[p^{\prime}\right]=\emptyset
\end{array}\right.
$$

Given the oddness filter in (31), we can still use the entry for $E x h^{p}$ in (25), repeated in (32), since this combination, as we will see, generates the desired predictions. On the other hand, we need to revise the strong presuppositional entry for only. Otherwise, $E x h^{p}$ and only would be incorrectly predicted to generate roughly the same oddness patterns for our target cases. Ideally, we should select an entry for only that (i) has been advanced on independent grounds and (ii) has a weaker presupposition than its prejacent. An obvious candidate is the nonpresuppositional entry in (33).

(32) Blind presuppositional $\boldsymbol{E} x \boldsymbol{h}^{p}$. Given $\phi$ and a set of excludable alternatives $\operatorname{Excl}(\phi), \operatorname{Exh}^{p}(\phi)$ presupposes the negation of all the (relevant) members of $\operatorname{Excl}(\phi)$ and asserts $\phi$ :

$$
\text { a. } \quad \operatorname{Exh}(\phi)=\left\{\begin{array}{l}
\text { ps: } \bigwedge \neg \psi: \psi \in \operatorname{Excl}(\phi) \cap R \\
\text { at-issue: } \phi
\end{array}\right.
$$

(33) Blind non-presuppositional only. Given $\phi$ and a set of excludable alternatives $\operatorname{Excl}(\phi), \operatorname{Only}(\phi)$ asserts the prejacent and the negation of all the (relevant) members of $\operatorname{Excl}(\phi)$ :

a. $\operatorname{Only}(\phi)=\phi \wedge \bigwedge \neg \psi: \psi \in \operatorname{Excl}(\phi) \cap R$

The revised blindness package in (31)-(33) can account for the full oddness pattern. Let us begin with the simplest cases. (27a), Some lions are mammals, is correctly predicted to be odd because, as before, its presupposition, $\neg$ All lions are mammals, clashes with the common ground. In addition, (28a), Some lions are robots, is correctly predicted to be felicitous (even if judged false): first, its presupposition, $\neg$ All lions are robots, is consistent with (indeed entailed by) the common ground; and second, although the update of its presupposition plus atissue content is inconsistent with the common ground, this is entirely due to a clash between the at-issue content (Some lions are robots) and the common ground. To see why this move is not filtered out by the revised ps-mismatch hypothesis in (31), notice that, whenever the presupposition itself is not inconsistent with the common ground, this filter only assigns oddness when the overall update, but not the at-issue content on its own, is inconsistent with the common ground. This condition is not satisfied in the case of (28a), since its at-issue content itself clashes with the common ground.

Consider next the more complex cases of the full oddness pattern. In contrast to the first version of the revised oddness package, this second version correctly predicts the oddness, given the ad hoc common ground $C$, of (29a), repeated below in (34a). To see this, focus on the presupposed vs. at-issue content of (34a), spelled out in (34e). Given the ad hoc information that Sue assigns her students the same grade, when the presupposition that not all of her students got an A is conservatively accommodated, we get the result that none of her students got an A. 
In addition, we can also consistently update $C$ with the at-issue/assertive content that Sue assigned an A to some students (the result being that Sue assigned an A to all of them). At this point, we can see, however, that the sequential update of $C$ with the presupposition and then the at-issue content generates an inconsistency. This kind of conversational move is filtered out by the second clause of the revised ps-mismatch hypothesis. As a result, (34a) is correctly predicted to be odd given the ad hoc common ground.

(34) Ad hoc C: Every year, Sue assigns the same grade to all her students.

a. \#This year, Sue assigned an A to some of her students.

b. LF: $\operatorname{Exh}^{p}$ [Sue assigned an A to some students] $=\operatorname{Exh}^{p}\left(\phi_{\exists}\right)$

c. $\quad \operatorname{Alt}\left(\phi_{\exists}\right)=\left\{\begin{array}{l}\phi_{\exists}=\text { Sue assigned an A to some students } \\ \phi_{\forall}=\text { Sue assigned an A to all students }\end{array}\right.$

d. $\phi_{\exists} \in R \wedge \phi_{\exists} \cap C=\phi_{\forall} \cap C \Rightarrow \phi_{\forall} \in R$

e. $\quad \llbracket(29 b) \rrbracket=\left\{\begin{array}{l}\text { ps: } \neg \text { Sue assigned an A to all students } \\ \text { at-issue: Sue assigned an A to some students }\end{array}\right.$

This revised package also makes correct predictions for the 'only' and 'some but not all' cases in our target oddness patterns. Starting with the former, the key case is (30a), repeated below in (35a). Given the non-presuppositional entry for only, the at-issue/assertive content of (35b) is that Sue assigned an A to some but not all of her students, as shown in (35d). This information is inconsistent with the ad hoc common ground $C$, and so the proposed revision and update could be rejected by the interlocutors. Still, since there is no clash, given the ad hoc $C$, between $C$ and the presupposed content, or between $C$ when conservatively updated with presupposed content and the at-issue content, which is not due to a direct clash between $C$ and the at-issue content on its own, (35a) is not filtered out by the revised ps-mismatch hypothesis. This is the correct result. ${ }^{17}$

(35) Ad hoc C: Every year, Sue assigns the same grade to all her students.

a. This year, Sue assigned an A to only some of her students.

b. LF: Only[Sue assigned an A to some students] $\quad=\operatorname{Only}\left(\phi_{\exists}\right)$

c. $\quad \operatorname{Alt}\left(\phi_{\exists}\right)=\left\{\begin{array}{l}\phi_{\exists}=\text { Sue assigned an A to some students } \\ \phi_{\forall}=\text { Sue assigned an A to all students }\end{array}\right.$

d. $\llbracket(35 \mathrm{~b}) \rrbracket=$ Sue assigned an A to some $\wedge \neg$ Sue assigned an A to all

Finally, let us consider one of the cases with an explicit 'some but not all' assertion, such as (36a) below. The basic observation, recall, is that they rank substantially higher in acceptability than their bare 'some' counterparts. In this case, the pre-

\footnotetext{
17 If we were to combine the strong presuppositional entry for only in (26) with the revised version of the ps-mismatch hypothesis in (31), we would incorrectly predict that (30a) is odd. For given these assumptions, the presupposed and at-issue content of (30a) is as in (30d). Crucially, while neither content is itself inconsistent with the common ground, when the ad hoc common ground incorporates the presupposition, the result is inconsistent with the at-issue content. This is precisely the kind of case that the revised ps-mismatch hypothesis was designed to filter out; hence this combination of assumptions incorrectly predicts that (30a) is odd. More generally, this combination of assumptions predicts that, in contexts in which $\operatorname{Exh}^{p}(\phi)$ is filtered out because it violates the second clause of the revised ps-mismatch hypothesis in (31), a matching sentence of the form only $(\phi)$ should also usually be filtered out (and vice versa). One of our key and novel observations, however, is that Exh and only don't generate the same oddness patterns in these kinds of cases, as illustrated also by patterns like (20)-(21).
} 
jacent is not contextually equivalent to its alternatives, as captured in (36d). For this reason, the only excludable alternative, $\phi_{\forall}$, need not be necessarily relevant. When that alternative is not relevant, $E x h^{p}$ is vacuous, hence (36a) has no presuppositions, and just the at-issue content of (36a) is inconsistent with the common ground. Again, this doesn't violate any condition of the revised ps-mismatch hypothesis, hence the assertion of (36a) is not predicted to be odd and can lead to revision of the common ground. In cases when $\phi_{\forall}$ is taken as relevant, $E x h^{p}$ does turn $\neg \phi_{\forall}$ into a presupposition (which is entailed by the at-issue content). However, the conflict with the ad hoc $C$ is still due to the full at-issue content, hence not filtered out by the ps-mismatch filter, and the assertion can lead the listener to revise the common ground.

(36) Ad hoc $C$ : Every year, Sue assigns the same grade to all her students.

a. This year, Sue assigned an A to some but not all of her students.

b. LF: $E x h^{p}$ [Sue assigned an A to some but not all students]

c. $\quad \operatorname{Alt}\left(\phi_{\exists}\right)=\left\{\begin{array}{l}\phi_{\exists}=\text { Sue assigned an A to some students } \\ \phi_{\forall}=\text { Sue assigned an A to all students }\end{array}\right.$

d. $\phi_{\exists} \wedge \neg \phi_{\forall} \cap C=\emptyset \neq \phi_{\exists} \cap C=\phi_{\forall} \cap C$

e. $\llbracket(36 \mathrm{~b}) \rrbracket=$ Sue assigned an $\mathrm{A}$ to some students $\wedge(\neg R$ (Sue assigned an A to all students) $\vee \neg$ Sue assigned an A to all students)

Summing up, the second version of the revised blindness package, presented in (31)-(33), can account for the full oddness pattern. This proposal incorporates some novel stipulations - relative to Magri's grammatical account - concerning the presupposed vs. at-issue content of Exh and only. In addition to its empirical advantages, a theoretical virtue of this revised package is that it uses an oddness filter - the revised ps-mismatch hypothesis in (31) - that is derived as a general principle of conversational dynamics, namely, as a reasonable constraint on accommodation (see Sect. 5.1). As a result, this account allows for felicitous assertions that call for revision - and not just adding information to - the common ground, as long as the controversial information is fully at-issue. Still, the revised blindness package preserves the core insights of Magri's original account of oddness, namely, that exhaustification is mandatory and excludes alternatives on the basis of a contextually blind, purely logical notion of entailment.

\section{Independent evidence for the revised blindness package}

The revised blindness package, I have argued, results in an attractive account of the full oddness pattern. Yet to be fully convincing, its core innovations should be independently in good standing. At a minimum, they should be empirically adequate with respect to established observations, with ordinary presupposition triggers, concerning oddness, accommodation and its limits, and also with respect to the sorts of cases used to motivate standard assumptions about the semantics of covert and overt exhaustification with only. The goal of this section is to begin to show that each of the core innovations of the revised blindness package is independently plausible. Sect. 5.1 discusses oddness patterns with standard presupposition triggers that support the ps-mismatch hypothesis. Sect. 5.2 presents independent evidence for the hypothesis that covert exhaustification is a presupposition trigger 
along the lines of $E x h^{p}$. Sect. 5.3 defends the proposal that we should drop the strong presuppositional entry for only in favor of a flatter one in which both the prejacent and the excluded alternatives are part of the assertive content.

5.1 The ps-mismatch hypothesis: oddness with standard presupposition triggers

I emphasized earlier that the revised blindness package uses an oddness filter, the 'ps-mismatch hypothesis' in (31), that is based on a general principle of conversational dynamics. The core observation is that it is generally hard for listeners to accommodate presuppositions that are inconsistent with the common ground. The underlying constraint, captured in the first part of (31), is that, in cooperative conversations, controversial information - especially when updating on it would require complex operations of belief revision - should be at issue, not presupposed (call this 'condition (i)'). The novel yet conservative extension of that constraint, captured in the second part of (31), says that all controversial information should be part of, or fronted to, the at-issue/assertive content, i.e., it cannot be distributed between the presupposed and at-issue content (call this 'condition (ii)'). The psmismatch hypothesis obviously applies beyond cases of Magri-style oddness. So even if one agrees with its theoretical motivation, its predictions should be tested against oddness patterns involving standard presupposition triggers.

Condition (i) of the ps-mismatch hypothesis - namely, that presuppositions should not be inconsistent with the common ground - is supported by many of the usual examples found in the literature on accommodation and its limits, such as the ones in (37) and (38) below, adapted from von Fintel (2008). Various standard accounts say that (37a) has an implicit domain restrictor and presupposes that everyone in the salient domain has a spouse. (37) explicitly sets the salient domain to the set of players on the target team, so that when it precedes (37a), the latter is forced to also quantify over that same salient domain. In addition, (37) entails (or 'Strawson-entails') that some players are single, which is inconsistent with the presupposition of (37a). So when an assertion of (37a) follows (37), the former is correctly predicted to feel odd by condition (i). This result can be avoided by explicitly restricting the target domain as in (37b).

(37) Not every player on this team is married...

a. \#but everyone loves their spouse.

b. but everyone who is married loves their spouse.

The dialogue in (38) below also captures a representative example of condition (i). Given the initial assertion by A, speaker B has good reason to conclude that A believes (and is perhaps merely reminding B that A believes) that it's actually part of their common ground that B doesn't have a sister, or at least that it would be controversial to assume otherwise. In this case, condition (i) correctly predicts that B cannot then felicitously assert a sentence with a presupposition that is inconsistent with that common ground, such as (38a), although B can call for belief revision by asserting the controversial information, as illustrated in (38b).

(38) A: Don't lie to me, I know for a fact that you don't have a sister.

a. B: \#I have to pick her/my sister up at the airport very soon. So I really have to go. 
b. B: I do have a sister, and I have to pick her up at the airport very soon. So I really have to go.

Condition (i) is also confirmed by odd cases involving factive verbs that trigger presuppositions that conflict with the common ground. For example, (39a) presupposes that two plus two may equal five. Since that (presupposed) proposition is inconsistent with normal background beliefs, (39a) is predicted to be odd given $C$ in (39). Under similar background conditions, that same proposition can be explicitly asserted and defended, i.e., used felicitously to try to change the common ground, as illustrated in (39b).

\section{$C$ : normal background beliefs about arithmetic}

a. \#John knows that two plus two may equal five.

b. It turns out that two plus two may equal five. And John knows that, although he is scared to admit it on Twitter.

Consider next condition (ii) of the ps-mismatch hypothesis. Take a common ground $C$, and an expression $\phi$ which presupposes $p$ and asserts $p^{\prime}$. Condition (ii) says that even if $p$ and $p^{\prime}$ are each independently consistent with $C$, if the sequential update $C[p]\left[p^{\prime}\right]$ results in inconsistency, then asserting $\phi$ given $C$ will still be odd. Again, this is the more novel part of our oddness filter, and independent cases that test its predictions are bound to be more controversial than the ones used to test condition (i). Still, suggestive cases can be found across various kinds of standard presupposition triggers.

For example, given the common ground $C$ in (40) below-i.e., which captures standard beliefs about the metaphysics of time, etc. - an assertion of (40a) seems odd. The presupposed proposition that John smoked for the first time at $t_{1}$ is compatible with $C$, and so is the at-issue proposition that John smoked for the first time at $t_{2}$ (s.t. $t_{1}<t_{2}<t_{\text {utterance }}$ ). However, the sequential update of $C$ with those two propositions results in an inconsistency. Accordingly, condition (ii) correctly predicts that (40a) should be odd given $C$.

$$
\begin{aligned}
& C: \text { time travel, changing the past, etc., is impossible } \\
& \text { a. } \quad \text { \#John smoked for the first time again. } \\
& \text { b. } \quad \llbracket(40 \mathrm{a}) \rrbracket= \\
& \quad\left\{\begin{array}{l}
\text { ps: John smoked for the first time at some time } t_{1} \\
\text { at-issue: John smoked for the first time at some time } t_{2}
\end{array}\right.
\end{aligned}
$$

A somewhat different kind of example is (41b), which is odd following the update of a normal common ground (where getting an 'A+' on a test entails that one passed the test) with the ad hoc information that only one student passed the test (cf. (41c)). Given a standard analysis of the trigger also, we get the presupposition and at-issue contents in (41b). Taken on its own, the presupposition that someone other than the referent of she got an $\mathrm{A}+$ is compatible with the background information that getting an $\mathrm{A}+$ entails a pass plus the ad hoc claim that only one student passed. The same applies to the at-issue information, taken on its own, that the referent of she got an $\mathrm{A}+$. Yet the sequential update with the presupposed and then the at-issue content obviously generates an inconsistency, and so is correctly predicted to be odd by condition (ii) of the ps-mismatch hypothesis. 
a. B: Yes! \#And she 1 also got an A+!

b. $\llbracket(41 \mathrm{a}) \rrbracket=\left\{\begin{array}{l}\text { ps: Some student other than she } 1 \text { got an } \mathrm{A}+ \\ \text { at-issue: } \mathrm{She}_{1} \text { got an } \mathrm{A}+\end{array}\right.$

c. B: Yes! And she even got an $\mathrm{A}+$ !

Sometimes whether an odd expression falls under condition (ii) depends on controversial hypotheses concerning the relevant/potential presupposition triggers. Consider an odd sentence with a definite description such as (42a) below. Given a modified Russellian analysis of the definite article - such that it presupposes the uniqueness condition-(42a) has the presupposition and at-issue contents in (42b), where $D^{\prime}$ stands for some salient subdomain of the domain of entities. Taken individually, each proposition is consistent with the common ground $C$ in (42). Yet the sequential update of $C$ with the uniqueness presupposition and the at-issue content generates an inconsistency (for any $x$, if $x$ is the unique author of book B, then $x$ is the main author of B). Accordingly, (42a) is correctly classified as odd by condition (ii). Unlike our other examples, this example is also a limiting case, since the sequential update is arguably inconsistent with any common ground. ${ }^{18}$

\section{$C$ : normal background information, but with no commitments with respect} to authorship of 'Philosophy: A Contemporary Introduction'

a. \#The author of Philosophy: A Contemporary Introduction is not its main author.

b. $\llbracket(42 \mathrm{a}) \rrbracket=$

$$
\left\{\begin{array}{r}
\text { ps: } \exists x \in D^{\prime} \text { s.t. } x \text { is the unique author of Phil } \\
\text { at-issue: } \exists x \in D^{\prime} \text { s.t. } x \text { is an author of Phil } \\
\wedge \neg x \text { is the main author of Phil }
\end{array}\right.
$$

Summing up, conditions (i) and (ii) of the ps-mismatch hypothesis seem to result in appropriate predictions for oddness patterns involving a wide range of standard presupposition triggers.

\subsection{Independent status of presuppositional exhaustification}

Let us now turn to the more innovative - and probably the most controversialcomponent of the revised blindness package, namely, the hypothesis that the covert exhaustification operator, $E x h^{p}$, is a presupposition trigger. My goal here is not to convincingly show that $E x h^{p}$ is, independently of its role in explaining Magristyle oddness, descriptively superior to other (non-presuppositional) formulations

\footnotetext{
18 If we assume instead Russell's original non-presuppositional analysis of the definite article, (42a) is not predicted to be odd by our oddness filter, and is expected to pattern, in terms of its degree of felicity, with other superficial contradictions, such as Triangles have four sides and This book has exactly one author but that author is not its main author. Such surface contradictions may seem absurd, ridiculous, or obviously false; but they don't seem to be strictly odd or infelicitous in the way our target examples are (of course, whether explicitly asserted contradictions are ultimately also ruled out as infelicitous depends on what additional oddness filters one adopts). Simplifications aside, this illustrates that the ps-mismatch hypothesis may be used - if reasonably confirmed - to discriminate between competing analyses of (potential) presuppositions triggers, given a range of oddness patterns involving those triggers.
} 
of exhaustification adopted by proponents of the grammatical approach. Rather, my aim is to present some intriguing empirical advantages of $E x h^{p}$, and open some promising lines for future research. ${ }^{19}$

\subsubsection{Are basic cases of scalar enrichments presuppositional?}

$\operatorname{Exh}^{p}(\phi)$ generates a non-trivial bifurcation of presupposed (the negated excludable alternatives of $\phi$ ) vs. assertive (the prejacent $\phi$ ) content. This result interacts appropriately with the ps-mismatch hypothesis, our oddness filter derived as a constraint on accommodation, in that (i) we predict Magri-style oddness, without (ii) blocking the possibility of felicitous assertions which call for radical revision of the common ground. This approach raises a natural worry, however: doesn't the view that exhaustification is a presupposition trigger negatively affect the treatment of ordinary examples of scalar enrichments? Consider a typical example of a scalar enrichment:

$C$ : compatible with Mary having done none, some, or all of the homework

a. A: Did Mary do the homework?

b. B: Mary did some of the homework.

Using non-presuppositional Exh, the result of the enrichment is as in (44a). In contrast, $E x h^{p}$ seems to trigger a default enrichment as in (44b), where $\neg \phi_{\forall}$ is presupposed (recall: we underline the presuppositions of formulas):

$$
\begin{array}{ll}
\text { a. } & \operatorname{Exh}\left(\phi_{\exists}\right)=\neg \phi_{\forall} \wedge \phi_{\exists} \\
\text { b. } & \operatorname{Exh}^{p}\left(\phi_{\exists}\right)=\neg \underline{\phi_{\forall}} \phi_{\exists}
\end{array}
$$

The worry here is that the $\neg \phi_{\forall}$ implicature of (43b) doesn't feel like a typical presupposition. More importantly, that scalar enrichment is obviously licensed in a context, such as $C$ in (43), which does not entail $\neg \phi_{\forall}$. Indeed, other familiar cases of scalar enrichments share the feature that the negation of the excludable alternatives may add new information to the common ground.

To respond to this worry, note that the ps-mismatch hypothesis, as formulated in (31), does allow for the (systematic/default) use of accommodation whenever (i) the presupposition of an assertion is consistent with the common ground and (ii) updating the common ground with that presupposition does not entail that the atissue content of the assertion is false. In other words, the ps-mismatch hypothesis is compatible with the following licensing condition on accommodation:

\footnotetext{
19 For a detailed defense of presuppositional exhaustification on independent grounds, see Bassi, Del Pinal, and Sauerland (2020) and Del Pinal, Bassi, and Sauerland (2020). In those papers, we argue that (blind) presuppositional $E x h^{p}$ has various empirical advantages over standard non-presuppositional accounts of exhaustification (and some recent presuppositional proposals) by examining how the predicted projection patterns of its presupposed content (the negated excludable alternatives) help solve various extant puzzles concerning the strange behavior of embedded scalar implicatures. Some of the cases discussed in this subsection are pursued more thoroughly in those papers, including a discussion of the possible advantages of implementing $E x h^{p}$ in a trivalent strong Kleene system.
} 
(45) Licensing condition on accommodation:

If $\phi\left(=\underline{p} p^{\prime}\right)$ is asserted in $C$ and $C \not \models \underline{p}$, you can move to a related $C^{\prime}$ such that $C^{\prime} \models \underline{p}$ unless (i) $\underline{p} \cap C=\emptyset$ or (ii) $\underline{p} \cap C \models \neg p^{\prime}{ }^{20}$

In light of this, consider again an assertion of (43b) in context $C$ of (43). Parsed with $E x h^{p}$, as in (44b), it would presuppose $\neg \phi_{\forall}$ and assert $\phi_{\exists}$. Obviously $C$ does not entail that $\neg \phi_{\forall}$. To determine if we can use global accommodation, we need to check that $\neg \phi_{\forall} \cap C \neq \emptyset$ and also that $\neg \phi_{\forall} \cap C \not \forall \neg \phi_{\exists}$, both of which clearly hold in this case. For the former, note that learning that Mary didn't do all of the homework, given $C$, still leaves open the possibilities that she did none or some of it. For the latter, note that learning that Mary didn't do all of the homework, given $C$, leaves open the possibilities that she did none or some of it. Since the licensing condition is satisfied, we can accommodate $\neg \phi_{\forall}$. More generally, we can assume that, for a presupposition trigger like $E x h^{p}$, accommodation is the default whenever the licensing condition is satisfied. This explains why in standard cases of unembedded scalar enrichments the presuppositions triggered by matrix $E x h^{p}$ need not be strictly entailed by the common ground and can thus be informative.

To be sure, some theorists reject notions like 'default accommodation', even when these are confined to specific presupposition triggers (see Simons et al. 2010). Yet even that position can, I think, be reconciled with a version of the revised blindness package which incorporates the following modifications: (i) $\operatorname{Exh}^{p}$ should be formulated as triggering at-issue (the prejacent) vs. non-at-issue content (the negation of each excludable alternative), and (ii) the ps-mismatch hypothesis should issue from a constraint according to which non-at-issue content in general should be consistent with the common ground. Now, as we will see in Sects. 5.2.2-5.2.4, $E x h^{p}$ predicts various non-trivial and attested projection patterns. Yet those results may be preserved if the presuppositional part is modeled instead as a different type of non-at-issue content that projects in similar ways (cf. (46a)). In addition, a ps-mismatch hypothesis based on non-at-issue content has some plausibility: e.g., it is odd to assert (46b) if it is common ground that Bill never participated in Wimbledon. Finally, the non-at-issue formulation would support the observation that, in general, non-at-issue information can be new-again, so long as it is not too controversial - as illustrated in (46c).

\section{$C$ : Bill never participated in Wimbledon.}

a. Mary doesn't think that Bill, who is a good coach, gives affordable lessons.

b. \# Bill, who won Wimbledon, gives affordable lessons.

c. Bill, who is a good coach, gives affordable lessons.

Summing up, treating covert exhaustification as a presupposition trigger doesn't negatively affect our account of basic cases of scalar enrichments. The next task is to present independent positive evidence for presuppositional $E x h^{p}$. Presupposi-

\footnotetext{
20 Some caveats: First, this formulation leaves open the possibility that, when the licensing condition is satisfied, we sometimes accommodate a presupposition $p$ by adding more information than is strictly contained in $p$. Second, it also leaves open the possibility that accommodation sometimes triggers some degree of belief revision to increase total coherence. Finally, licensing conditions might have to be relativized to particular kinds of presupposition triggers, since some triggers (such as $\operatorname{Exh}^{p}$ on the view defended here) are much more liberal than others in allowing for default accommodation.
} 
tion triggers generate non-trivial projection patterns, especially when they appear in embedded positions. Accordingly, we can test whether the presuppositions triggered by $E x h^{p}$ project in the expected ways. In the next subsections, I argue that not only is this attested, but treating the (negated) excludable alternatives as presuppositions helps solve various extant puzzles for grammatical theories of exhaustification.

\subsubsection{Exhaustification under negation}

As Horn (1989), Fox and Spector (2018), and others point out, examples like (47a), if read without special intonation, do not allow for the reading that can be described as enriching inclusive-or to exclusive-or under negation. Yet the parse in (47b) with Exh under negation generates that weak reading, which would in turn license the continuation in (47a).

$$
\begin{aligned}
\text { a. } & \text { Alex didn't talk to Mary or Sue. (\#She talked to both.) } \\
& \sim \neg \phi_{\text {Mary }} \wedge \neg \phi_{\text {Sue }} \\
\text { b. } & \neg[E x h[\text { Alex talked to Mary or Sue }]] \\
& =\neg\left(\phi_{\text {Mary }} \vee \phi_{\text {sue }} \wedge \neg\left(\phi_{\text {Mary }} \wedge \phi_{\text {Sue }}\right)\right) \\
& \approx \text { Alex talked to neither or to both }
\end{aligned}
$$

Standard grammatical accounts need some justification for blocking the parse in (47b). Fox and Spector (2018) propose an economy condition which, based on a defeasible preference for strong readings, bars Exh in downward-entailing environments.

In contrast, $E x h^{p}$ makes available a direct explanation of these cases which doesn't require any additional constraints (see Bassi et al. 2020). Consider the parse in (48a) for (47a), which is similar to (47b) except that we replaced Exh with $E x h^{p}$. The embedded $E x h^{p}$ triggers the presupposition that Alex didn't talk to Mary and Sue. But since it is a presupposition, it projects through negation, as shown in (48b). As a result, it doesn't weaken the overall reading and is ultimately innocuous, since it is entailed by the assertive part.

$$
\begin{array}{ll}
\text { a. } & \neg\left[E x h^{p}[\text { Alex talked to Mary or Sue }]\right] \\
\text { b. } & =\neg\left(\neg\left(\phi_{\text {Mary }} \wedge \phi_{\text {Sue }}\right)\right. \\
& \left.\phi_{\text {Mary }} \vee \phi_{\text {Sue }}\right)=\neg\left(\phi_{\text {Mary }} \wedge \phi_{\text {Sue }}\right) \wedge \neg\left(\phi_{\text {Mary }} \vee\right. \\
& =\neg\left(\phi_{\text {Mary }} \vee \phi_{\text {sue }}\right)
\end{array}
$$

$E x h^{p}$ also helps with the other part of the puzzle, namely, that implicatures under negation can be observed under certain conditions. Consider first the more general phenomenon of presupposition cancelation under negation. When the 'contradiction contour' is used, presuppositional content under the scope of negation can be cancelled - and seems to become at-issue - as can be seen by the acceptability contrasts in (49) and (50):

(49) a. Mary isn't late to the meeting again ...\# Hhe has never been late before!

b. Mary isn' $t_{H *}$ late to the meeting $\operatorname{AGAIN}_{L+H * L H \%} \ldots$ she has never been late before!

a. Mary didn't stop smoking ... \# she never smoked! 
b. Mary didn't ${ }_{H *} \mathrm{STOP}_{L+H *} \operatorname{smoking}_{L H \%} \ldots$ she never smoked!

Suppose that in these kinds of cases presupposition cancellation is possible due to local accommodation, which we assume is computed by the ACC operator, where $\operatorname{ACC}\left(p p^{\prime}\right)=p \wedge p^{\prime}$ (Heim 1983). This would, in turn, generate the prediction that, under similar intonation conditions, the presuppositions triggered by $E x h^{p}$ under negation in our original examples should be cancellable, and the previously unattested weak reading become available. As pointed out in Horn (1989), and further discussed in Meyer (2016) and Fox and Spector (2018), this prediction clearly obtains, as illustrated in (51a). Parallel to accounts of presupposition cancellation in $(49 \mathrm{~b})$ and $(50 \mathrm{~b})$, these conditions license the parse in $(51 \mathrm{~b})$, which generates the target weak reading - namely, that Alex talked to neither or to both of Mary and Sue - which is in turn compatible with the target continuation. ${ }^{21}$
a. Alex didn't ${ }_{H *}$ talk to Mary $\mathrm{OR}_{L+H *}$ Sue $_{L H \%} \ldots$ She talked to both!
b. $\neg\left[\operatorname{ACC}\left[\operatorname{Exh}^{p}[\right.\right.$ Alex talked to Mary or Sue $\left.\left.]\right]\right]$
c. $\quad\left(\phi_{\text {Mary }} \wedge \phi_{\text {Sue }}\right) \wedge \neg\left(\phi_{\text {Mary }} \vee \phi_{\text {sue }}\right)$

\subsubsection{Exhaustification under 'some'}

Consider the sentences in (52) and (53). Gotzner and Benz (2018) report evidence that subjects prefer the reading with local enrichment for (52) and the one with global enrichment for (53). They argue that this presents a challenge to various accounts of scalar implicatures. In particular, they show that neo-Gricean accounts (when implemented without access to embedded implicatures) make the correct prediction for the enrichment of (53), but not for (52); whereas grammatical accounts along the lines of Chierchia (2004) - which in these cases make similar predictions to Magri's account with obligatory Exh-make the correct prediction for (52), but not for (53).

(52) All of the girls found some of their marbles.

a. Local enrichment: All of the girls found some but not all of their marbles.

b. Global enrichment: All of the girls found some of their marbles and not all of the girls found all of their marbles.

\footnotetext{
21 There is another interesting prediction, in light of the connection between the contradiction contour and licensing of local accommodation, for accounts of oddness. Global accommodation and local accommodation at matrix level should be strictly distinguished. Now consider examples like those of Magri-style oddness but with an intonation pattern that normally licenses local accommodation at the matrix level, roughly along the lines of \SOME LIONS/are mammals and \SOME ITALIANS/ come from a beautiful country. Given our current assumptions, that would in turn arguably license the parses in (ia) and (ib) with matrix-level local accommodation:

(i) a. $\quad \operatorname{ACC}\left[\operatorname{Exh}^{p}[\right.$ some lions are mammals $\left.]\right]$

b. $\operatorname{ACC}\left[E x h^{p}[\right.$ some Italians come from a beautiful country $\left.]\right]$

The result is that, under these conditions, the corresponding expressions no longer fall under the ps-mismatch hypothesis (again, assuming a licensing distinction between global accommodation and matrix-level local accommodation), and are thus predicted to feel less odd and more adequate as ways to signal to the listener that the common ground should be revised, compared to the original examples without such intonation. This prediction seems to me to be roughly correct, but is admittedly subtle and requires further empirical investigation.
} 
(53) Some of the girls found some of their marbles.

a. Local enrichment: Some of the girls found some but not all of their marbles.

b. Global enrichment: Some of the girls found some of their marbles and none of the girls found all of their marbles.

Focusing on grammatical accounts, consider the LF in (54a) for (53). The key observation - and challenge - is that if we use non-presuppositional Exh, this LF generates the non-preferred local enrichment, as captured in (54b) (no other parse generates the preferred global enrichment). In contrast, if we use $E x h^{p}$, as in (55a), we generate the preferred global enrichment, as captured in (55b) (see Bassi et al. 2020). This is because the negation of the excludable $\forall$-alternative triggered by the embedded $E x h^{p}$ - underlined in (55b) to mark its status as a presuppositionarguably projects universally over $x$. (It is easy to check that a parse parallel to (55a) also predicts the desired local enrichment reading for (52).)

\section{With standard Exh:}

a. $\operatorname{Exh}\left[\right.$ some of the girls $\lambda_{x} E x h$ [some of their marbles $\lambda_{y}[x$ found $\left.y]\right]$

b. $=\operatorname{Exh}\left[\right.$ some of the girls $\lambda_{x}$ [ all of their marbles $\lambda_{y}[x$ found $y] \wedge$ some of their marbles $\lambda_{y}[x$ found $\left.\left.y]\right]\right]$

With presuppositional $E x h^{p}$ :

a. $\operatorname{Exh}^{p}$ [some of the girls $\lambda_{x} \operatorname{Exh}^{p}$ [some of their marbles $\lambda_{y}[x$ found $y]]]$

b. $\quad=E x h^{p}\left[\right.$ some of the girls $\lambda_{x}$ [حall of their marbles $\lambda_{y}[x$ found $y]$ some of their marbles $\lambda_{y}[x$ found $\left.\left.y]\right]\right]$

As Gotzner and Benz point out, although in their experimental setting the global enriched reading for (53) was preferred, in other contexts the local reading might be preferred. An attractive feature of $E x h^{p}$ is that we can recover such readings via the interaction between $E x h^{p}$ and local accommodation (recall that $\left.\operatorname{ACC}\left(\underline{p}^{\prime}\right)=\mathrm{p} \wedge \mathrm{p}^{\prime}\right)$ :

(56) With presuppositional $E x h^{p}$ under ACC:

a. $E x h^{p}$ [some of the girls $\lambda_{x} \operatorname{ACC}\left[E x h^{p}\right.$ [some of their marbles $\lambda_{y}[x$ found $y]]]]$

$=\operatorname{Exh}^{p}$ [some of the girls $\lambda_{x}\left[\neg\right.$ all of their marbles $\lambda_{y}[x$ found $y] \wedge$ some of their marbles $\lambda_{y}[x$ found $\left.\left.y]\right]\right]$

As in the case of exhaustification under negation, since an accommodation operator like ACC is arguably independently needed by any theory that appeals to semantic presuppositions, we gain this added flexibility in the system essentially for free. ${ }^{22}$ At the same time, we can maintain the prediction that the parse without local ACC

22 This observation can also be used to account for related results reported in the experimental literature. Potts et al. (2016) report that Exacly one player made some of his shots was endorsed by around half of the subjects in a scenario where exactly one player made some but not all shots and one or both of the other players made all shots. Why don't we get the universal projection here that none of the players made all of the shots? The availability of an LF analogous to the one in (56) helps answer this question, at least given some reasonable story for why it might be preferred in the experimental task/context. 
is the default, when compatible with the global context, since it triggers stronger presuppositions.

\subsubsection{Exhaustification under factive attitudes}

Gajewski and Sharvit (2012) discuss the peculiar behavior of exhaustification under factive attitudes (see also Spector and Sudo 2017 and Marty and Romoli 2020). While the target cases present a problem for standard accounts of Exh, as they argue, such cases can be directly handled with $E x h^{p}$.

To illustrate the challenge, consider (57a) and (57b) in a context like (57). The target reading for (57a) is that Jasmine did some but not all of the homework, and the one for (57b) is that while Jasmine did some but not all of the homework, John doesn't believe that she did any of it. Why does this present a challenge for standard Exh? Given the parse in (58a), we get the target reading for (57a), i.e., the one with the $\neg \phi_{\forall}$-enrichment. In the case of (57b), where (57a) appears embedded under a factive propositional attribution, that same parse does get us part of the target reading, namely, the $\neg \phi_{\forall}$-enrichment, as captured in (58b). However, it misses the intended prediction for the content of John's beliefs. On the target reading, what John doesn't believe is that Mary did any of the homework, not that Mary did some but not all (which is compatible with John's believing that Mary did all). Finally, the parse in (58c) doesn't help: although it does make the correct prediction for John's attitude (that he doesn't believe that Jasmine did any of the homework), it misses the $\neg \phi_{\forall}$-enrichment (note: in this case no alternatives to the prejacent are excludable).

$C$ : Jasmine did none, some, or all of the homework.

Question under discussion (QUD): How much of the HW did Jasmine do?

a. Jasmine did some of the homework.

$\sim \neg \phi_{\forall} \wedge \phi_{\exists}$

b. John is unaware that Jasmine did some of the homework. $\leadsto \neg \phi_{\forall} \wedge \phi_{\exists} \wedge \neg B_{J}\left(\phi_{\exists}\right)$

(58) a. Exh[Jasmine did some of the homework] $=\neg \phi_{\forall} \wedge \phi_{\exists}$

b. John is unaware $\operatorname{Exh}[$ Jasmine did some of the homework] $=\neg \phi_{\forall} \wedge \phi_{\exists} \neg B_{J}\left(\neg \phi_{\forall} \wedge \phi_{\exists}\right)$

c. $E x h\left[\right.$ John is unaware that Jasmine did some ${ }_{F}$ of the homework] $=\phi_{\exists} \neg B_{J}\left(\phi_{\exists}\right)$

Consider next the predictions with $E x h^{p}$. In the case of (59a), we get the standard entailment that Jasmine did some but not all of the homework. As before, the real challenge is $(57 \mathrm{~b})$. We continue to assume that John is unaware that $p$ presupposes $p$ and asserts that John doesn't believe $p$. Accordingly, the parse in (59b) gets us the reading in (59c). And since $E x h^{p}$ is a presupposition trigger, the belief operator itself has a complement with a presupposition. Following Heim (1992), let us assume that $B\left(p p^{\prime}\right)$ presupposes $B(p)$ and asserts $B\left(p^{\prime}\right)$ (cf. Mary believes that John is smoking again, which presupposes that Mary believes that John smoked in the past and asserts that Mary believes that John is smoking around utterance time). Given this assumption, we can derive the first equivalence in $(59 \mathrm{~d})$; and since negation is a presupposition hole, we can also derive the second 
equivalence in $(59 \mathrm{~d})$. The resulting reading is the one in (59e), which has all the desired entailments.

$$
\begin{array}{ll}
\text { a. } & E x h^{p}[\text { Jasmine did some of the homework] } \\
=\neg \phi_{\forall} \phi_{\exists} \\
\text { b. } \quad \text { John is unaware } \operatorname{Exh}^{p}[\text { Jasmine did some of the homework] } \\
\text { c. } \quad \llbracket(59 \mathrm{~b}) \rrbracket=E x h^{p}\left(\phi_{\exists}\right) \neg B_{J}\left[\operatorname{Exh}^{p}\left(\phi_{\exists}\right)\right] \\
\text { d. } \quad \neg B_{J}\left[E x h^{p}\left(\phi_{\exists}\right)\right]=\neg\left[B_{J}\left(\neg \phi_{\forall}\right) B_{J}\left(\phi_{\exists}\right)\right]=\underline{B_{J}\left(\neg \phi_{\forall}\right)} \neg B_{J}\left(\phi_{\exists}\right) \\
\text { e. } \quad \llbracket(59 \mathrm{~b}) \rrbracket=\left\{\begin{array}{l}
\text { ps: } \neg \phi_{\forall} \wedge \phi_{\exists} \wedge B_{J}\left(\neg \phi_{\forall}\right) \\
\text { at issue: } \neg B_{J}\left(\phi_{\exists}\right)
\end{array}\right.
\end{array}
$$

Now, we also predict an extra presupposition that is arguably unattested in this example, namely, that John believes that Jasmine didn't do all of the homework $\left(=B_{J}\left(\neg \phi_{\forall}\right)\right)$. Yet this is simply due to the independent auxiliary assumption that a belief operator with a presupposition in its complement, as in $B\left(p p^{\prime}\right)$, triggers $B(p)$ as a presupposition. There are competing accounts (e.g., some versions of DRT) which predict a stronger presupposition, namely, that $B\left(p p^{\prime}\right)$ presupposes $p$ (see e.g., Geurts 1999). In the case of (59b), this would get us exactly the desired result; so we could opt instead for this alternative auxiliary assumption if it turns out that it works better in general.

Marty and Romoli (2020) discuss other, related examples that can be handled by a modified version of a system in which, following Gajewski and Sharvit (2012), exhaustification affects (with some subtle difference) both content that is presupposed by its prejacent and also the assertive content of its prejacent. Those kinds of accounts are designed to handle somewhat different cases than the ones that motive the claim advanced here that exhaustification is a presupposition trigger. Although ultimately our account of presuppositional exhaustification might have to be enriched/modified into some kind of multi-dimensional operator, Del Pinal et al. (2020) try to show that most of the other patterns introduced and discussed in Marty and Romoli (2020) can also be handled directly with $E x h^{p}$, including the phenomenon of presupposed free choice.

Let us sum up our discussion of the independent status of presuppositional exhaustification in the context of grammatical approaches to scalar implicatures. On the one hand, replacing $E x h$ with $E x h^{p}$ doesn't negatively affect our account of basic unembedded examples of scalar enrichments. On the other hand, we have seen some suggestive evidence that $E x h^{p}$ has important advantages when it comes to explaining the complex projection behavior of scalar enrichments in various kinds of embedded environments.

\subsection{Independent status of non-presuppositional only}

The third and final component of the revised blindness package that we need to consider is the hypothesis that only has a relatively flat structure, as in (33). Isn't this hypothesis in tension with standard observations traditionally used to support the strong presuppositional account according to which only $\phi$ presupposes $\phi$ ? I will argue that those cases are compatible with a non-presuppositional account of only, if the latter is combined with a presuppositional account of covert exhaustification, $E x h^{p}$, as in the revised blindness package. I will also present novel variations of 
standard cases which support the package of a relatively flat entry for only and a presuppositional entry for covert exhaustification. ${ }^{23}$

The basic argument for a strong presuppositional entry is based on the perceived generalization that, when only $\phi$ is embedded in environments that are typically holes to presuppositions, the prejacent, $\phi$, projects as if it was a presupposition (see Horn 1969; Rooth 1992; Roberts 2011). Representative examples include embedding only $\phi$ in the antecedents of conditionals, as in (60a), under questions, as in (60b), and under negation, as in (60c). The generalization is that $\phi$ seems to 'project out' of (not fall under the scope of) the antecedent, interrogative, and negation environments/operators (depending on the theory of projection, the prejacent may also be expected, in each case, to be entailed by the global context):

(60) a. If only Sue and John passed, the exam was just too hard.

$\leadsto$ Sue and John passed

b. Did only Mary and Peter go to the party?

$\leadsto$ Mary and Peter went to the party

c. $\{$ It's not the case that/Not\} only John passed the exam. $\leadsto$ John passed the exam

Let us begin with the conditional and interrogative embeddings in (60a)-(60b). As others have pointed out, these cases do not amount to uncontroversial evidence for the strong presuppositional account, partly because it isn't clear whether the prejacent of only reliably projects. To see the problem, consider the cases in (61a)(61b). The key observation is that a speaker $S$ can felicitously assert (60a) in a broader context which entails that $S$ isn't committed to the truth of the prejacent of the embedded only-statement:

(61) a. I don't know if anyone passed the exam. Yet/But if only Sue and John passed, the exam was just too hard. (Sue and John are exceptional students!)

b. If only Sue and John passed, the exam might have been too hard. Yet/But if no one passed, it was definitely too hard. (Sue and John are exceptional students!)

The target readings of the conditionals in (61a) and (61b) are closer to those predicted by a flat entry for only, according to which in each case the prejacentand not just the negation of the excludable alternatives - is part of the content of the antecedent. Proponents of the strong presuppositional account might argue that these cases trigger local accommodation within the antecedent, an operation that is in each case licensed to avoid an obvious inconsistency. The problem with this response is that analogous cases with paradigmatic presupposition triggers are not rescuable from oddness by the hypothesized local accommodation operation (at least not without special intonation), as illustrated in (62a)-(62c):

a. I don't know if anyone passed the exam. \#Yet/But if Jasmine realizes/finds out that only Sue and John passed, she will be very angry.

\footnotetext{
23 Although the strong presuppositional account is still popular, various theorists have defended, on independent grounds, a weak or even non-presuppositional entry for only (e.g., Ippolito 2007; van Rooij and Schulz 2007).
} 
b. I don't know if anyone passed the exam. \#Yet/But if John also passed, the exam was definitely too easy.

c. If John and Peter also passed the exam, it was probably at an appropriate level. \#Yet/But if no one passed, it was definitely too hard.

Parallel points apply to polar questions such as (60b), repeated (with minor modifications) in (63). For example, the positive answer in (63a) can coherently target and provide non-redundant evidence for both the prejacent and the exclusive proposition of the only-claim embedded under the interrogative. Similarly, the negative answer in (63b) can coherently target and provide evidence against the prejacent (this is compatible with the observation that these sort of polar questions tend to make the excluded alternatives more at-issue than the prejacent, as suggested by examples in which the excluded alternatives are the sole target of Yes/No answers).

(63) Q: From our students, did only Mary and Peter attend the party?

a. A: Yes! I saw Mary and Peter enter the party, and I also searched carefully the rest of the night and didn't see anyone else.

b. A: No! I searched carefully and not even Mary and Peter were there.

These observations are not surprising if the prejacent of only also falls under the scope of the interrogative, as predicted by the flat account. Advocates of the strong presuppositional account might agree that (63)-(63a) and (63)-(63b) are coherent question-answer dialogues, yet try to explain that by appealing to local accommodation of the prejacent of only. The problem with this suggestion, as in the case of conditionals, is that analogous question-answer dialogues with paradigmatic presupposition triggers are not rescuable from infelicity by the hypothesized local accommodation operation, as illustrated in (64)-(64a) and (64)-(64b):

(64) Did John find out that Mary and Peter attended the party?

a. A: Yes! \#I saw Mary and Peter enter the party, and John told me he saw them in the VIP room.

b. A: No! \#I searched carefully and Mary and Peter weren't at the party.

The standard cases with conditionals and questions, then, do not uniquely support the strong presuppositional account of only. In addition, the observations in (61)(64) provide some support for a relatively flat entry for only.

However, arguably the strongest and most influential argument for a strong presuppositional account is based on the observation that both plain and negated only-clauses seem to entail or imply the prejacent of only. For example, both (65a) and (65b) seem to imply that John passed. This suggests that, in (65b), the prejacent of only projects through negation - a pattern that is as expected if only $\phi$ presupposes $\phi$ (Horn 1969; Rooth 1992).

a. Only John passed the exam.

$\sim$ John passed

b. Not only John passed the exam.

$\leadsto$ John passed

The challenge for the revised blindness package, then, is to derive this pattern using a flat instead of a strong presuppositional account of only. Interestingly, our approach makes correct predictions in these cases, given the defensible auxiliary assumption that structurally simpler expressions obtained by deletion of focused 
material in a target expression $\psi$ are amongst the formal alternatives of $\psi$ (Fox and Katzir 2011). This account predicts that (65a) and (65b) have an LF with covert $E x h^{p}$, as in (66a) and (66b):
a. $E x h^{p}$ [only John passed the exam]
b. $E x h^{p}[\neg$ only John passed the exam $]$

$$
\begin{array}{r}
=\operatorname{Exh}^{p}\left(\phi_{\text {only }}\right) \\
=\operatorname{Exh}^{p}\left(\neg \phi_{\text {only }}\right)
\end{array}
$$

For the intended readings, the embedded only associates with John and Exh associates with only. As a result, the alternatives for $E x h^{p}$ in (66a) are arguably $\phi_{\text {only }}$ and the plain prejacent $\phi$, as captured in $(67 \mathrm{a})$; and in the case of $(66 \mathrm{~b})$, the alternatives for $E x h^{p}$ are the negated counterparts, as captured in (67b) (cf. Romoli 2011, 2015).

$$
\begin{aligned}
& \text { a. } \quad \operatorname{Alt}\left(\phi_{\text {only }}\right)=\left\{\begin{array}{l}
\phi_{\text {only }}=\text { only John passed } \\
\phi=\text { John passed }
\end{array}\right. \\
& \text { b. } \quad \operatorname{Alt}\left(\neg \phi_{\text {only }}\right)=\left\{\begin{array}{l}
\neg \phi_{\text {only }}=\neg \text { only John passed } \\
\neg \phi=\neg \text { John passed }
\end{array}\right.
\end{aligned}
$$

When $E x h^{p}$ takes a bare only-clause, as in (66a), its effect is vacuous: $\phi_{\text {only }}$ obviously entails each of its alternatives in (67a), hence no alternatives are excludable. ${ }^{24}$ But when $E x h^{p}$ takes a negated only-clause, as in (66b), it has a non-trivial effect, given the alternatives in (67b): for the prejacent, $\neg \phi_{\text {only }}$, does not entail its $\neg \phi$-alternative (e.g., $\neg \phi_{\text {only }}$ is true while $\neg \phi$ is false if John and any other relevant student passed). Accordingly, the $\neg \phi$-alternative is negated, which leads to the desired entailment that John passed the exam. So we can derive the observed presupposition-like effect, for cases like (65b), without adopting a strong presuppositional entry for only. ${ }^{25}$ The source of this effect comes instead from the interaction between presuppositional $E x h^{p}$ and a flat only, given the intervention effect of negation.

According to the revised blindness package, then, there is an important difference between the perceived entailment of the prejacent $\phi$ in instances of 'only $\phi$ ' vs. ' $\neg$ only $\phi$ '. While sentences of both kinds are obligatorily exhaustified, only in the latter does $E x h^{p}$ trigger the presupposition that $\phi$. Going back to (65a) and $(65 \mathrm{~b})$, this means that in $(65 \mathrm{~b})$ the perceived entailment that John passed is really a presupposition triggered by matrix level $E x h^{p}$. In contrast, on the strong presuppositional account, the perceived entailment that $\phi$ has the same presuppositional status in instances of 'only $\phi$ ' and ' $\neg$ only $\phi$ '. Applied to (65a) and (65b), the proposition that John passed is in both cases treated as a presupposition. To determine whether the blindness package has an advantage here, we can exam-

\footnotetext{
24 The result that we get vacuous exhaustification when $E x h^{p}$ associates with a non-negative only-clause is the reason why I didn't consider, in the discussion of the full oddness pattern in Sect. 4, parses for the only-sentences with matrix Exh. In those cases, widest scope/matrix $\operatorname{Exh}^{p}$ is vacuous.

25 It is easy to check that this account derives appropriate overall truth conditions for (65b). For simplicity, suppose that the other relevant students are Sue and Peter. Given a flat entry, the embedded only-claim reduces to 'John passed $\wedge \neg$ at least one of Sue or Peter passed'; when that conjunction is negated, we get ' $\neg$ John passed $\vee$ at least one of Sue or Peter passed'. Since (65b) presupposes that John passed, the first disjunct can't hold without triggering presupposition failure. As a result, $(65 \mathrm{~b})$ is defined iff John passed, and when defined, is true if Sue or Peter passed and false if neither Sue nor Peter passed. These are the appropriate truth conditions for (65b), given the focus/information structure under consideration.
} 
ine whether the proposition that John passed projects like a presupposition when (65b) - but not when (65a) - is embedded in certain environments.

To test that, consider the default readings of (68a) and (68b) below, focusing on the subtle contrast in the content of the factive attitude in each case. The content of Mary's realization event in (68a) is that John passed and no one else did, whereas (68b) conveys that Mary knew/believed that John passed and that the content of the realization event is that someone other than John also passed. Importantly, this reading of $(68 \mathrm{~b})$ parallels that of structurally analogous expressions with standard presuppositions triggers. For example, (68c) conveys that the content of Mary's realization event is specifically that John is smoking around utterance time (given that Mary already knew/believed that John smoked in the past), and not that Mary realized both that John smoked in the past and is smoking again around utterance time.

(68) a. Mary realized/found out that only John passed the exam.

b. Mary realized/found out that not only John passed the exam.

c. Mary realized/found out that John is smoking again.

The proposed difference between (68a) and (68b) is brought out by a specific contrast in the kind of information that can coherently admit analogous assertions. Given the information in (69) - which entails that before, or independently of, the target event of 'finding out' the speaker didn't believe/know whether John passed - asserting (69a) seems fine whereas (69b) seems somewhat odd. This is as expected if just (69b) presupposes that John passed: for this presupposition would clash with what the speaker explicitly denied believing/knowing prior to the target realization event. Furthermore, in analogous conditions, minimal variants with typical presupposition triggers are similarly odd, as illustrated in (70) by the contrast between the continuations in (70a) and (70b).

(69) Since I didn't know whether anyone passed the exam, I just checked in the system and...

a. (I) found out that only John passed.

b. ??(I) found out that not only John passed.

(70) Since I didn't know whether John used to smoke, I just checked the security cameras and...

a. (I) found out that he did use to smoke.

b. ??(I) found out that he is smoking again.

The partial LFs in (71a) and (71b) for, respectively, (68a)/(69a) and (68b)/(69b) capture the target contrast - assuming that in both LFs Exp ${ }^{p}$ associates with only and only with John. For as shown before, while the embedded $E x h^{p}$ is vacuous in (71a), in (71b) it triggers as a presupposition that John passed, which then projects through the embedding attitude operator.

a. Mary/I realized/found out $E x h^{p}$ [only John passed the exam]

b. Mary/I realized/fount out $\operatorname{Exh}^{p}[\neg$ only John passed the exam]

Finally, the contrast between $(68 \mathrm{a}) /(69 \mathrm{a})$, on the one hand, and $(68 \mathrm{~b}) /(69 \mathrm{~b})$, on the other, is hard to explain - at least without additional stipulations - given the strong presuppositional account of only. For on this view, (68a)/(69a) and 
(68b)/(69b) all presuppose that John passed the exam, hence should be uniformly odd in contexts like (69). ${ }^{26}$

The predictions of the revised blindness package concerning the presupposed vs. assertive content of bare and negated only-sentences also help account for certain well-known cases, involving embeddings under modals, that have been used to challenge the strong presuppositional account of only (see Horn 1996; Geurts and van der Sandt 2004; Ippolito 2007. The target contrast is illustrated in (72a)(72b), where the key observation is that, unlike a standard presupposition, the prejacent of only doesn't seem to project when embedded under an existential or bare possibility modal:
a. It's possible that only John can speak French. $\chi_{\rightarrow}$ John can speak French
b. It's possible that John regrets having smoked. $\leadsto$ John smoked

The suggested pattern of entailments is further supported by the difference in felicitous continuations to (72a) and (72b) captured in (73a) and (73b):
a. It's possible that only John can speak French... and maybe not even he can.
b. It's possible that John regrets having smoked.... \#and maybe he never smoked.

If (72a) presupposed the prejacent of the embedded only, then it should project in a way that parallels how the factive presupposition projects in $(72 \mathrm{~b})$. In a discourse like (73a), the continuation that maybe John can't speak French would then clash with the prior commitment that John can speak French. This incorrectly predicts that the continuation in $(73 \mathrm{a})$ should be roughly as odd as the one in $(73 \mathrm{~b})$. That is, if only $\phi$ presupposes $\phi$, why doesn't the prejacent of the embedded only in (72a) project through the possibility modal in way that parallels how the factive presupposition projects in $(72 \mathrm{~b})$ ? In contrast, on the revised blindness package, when a bare only-clause, such as the embedded 'only John can speak French' in (72a), is directly exhaustified, we can't exclude any alternative, hence no presuppositions are triggered. ${ }^{27}$ In addition, due to the flat entry for only, the

\footnotetext{
26 Two observations further support the core assumptions of the revised blindness package. First, consider what would happen if the LFs in (71a) and (71b) were formulated with standard Exh, rather than presuppositional $E x h^{p}$. In $(71 \mathrm{~b})$ both the prejacent and the excluded alternatives would be at-issue; so the reading we would get, when Exh associates with only, is instead the non-default one that John's having passed the exam is part of the content of what Mary realized. Since this is perfectly consistent given information like that in (69), we would lose the explanation of the contrast in acceptability between the continuations in (69a) and $(69 \mathrm{~b})$. Second, consider what would happen if exhaustification was not obligatory. Then the embedded only-clause in (68b) would not need to be exhaustified, and we would lose the explanation for why (69b) is odd as a continuation of (69). Of course, even if we fixed the focus structure, the obligatory exhaustification operation in $(71 \mathrm{~b})$ could also be trivialized by the effect of relevance - but we are assuming, plausibly, that in most contexts where ' $\neg$ only John passed' (which, given the flat only, amounts to ' $\neg$ John passed $\vee$ at least one other student passed) is relevant, so is ' $\neg$ John passed'.

27 Matrix $E x h^{p}$ in (72a) doesn't change the target result, namely, that (72a) doesn't presuppose that John can speak French. This is easy to check (e.g., if it associates with possible we get a ' $\neg$ certain' enrichment), but let me illustrate by considering one potentially relevant parse. Suppose matrix $E x h^{p}$ associates with only. The prejacent of $E x h^{p}$ in this case would be
} 
conjunction that John can speak French and that no one else can (in the relevant domain) falls under the scope of the possibility modal. That content is obviously compatible with the continuation in (73a). Finally, this account predicts that, if in a case like (72a), we add negation over the embedded only-clause - and maintain the relevant associations between $E x h^{p}$, only, and John - the prejacent of only will be triggered as a presupposition. In cases like (74), this predicts a clash between the presupposition of the first assertion (John can speak French) and the continuation $(\diamond \neg$ John can speak French), which seems like the correct result:

It is possible that not only John can speak French...

??and maybe not even he can.

Summing up, we have examined various standard cases used to support the strong presuppositional account of only. We have seen that the revised blindness package can account for the basic cases while assuming that only $\phi$ doesn't presuppose $\phi$. Furthermore, this approach can deal with a range of simple variations which are problematic for the strong presuppositional account, including cases involving embedded positive only-clauses in which the prejacent doesn't behave like a presupposition. These preliminary results merit further investigation, but they suggest that we can continue to work with a version of the revised blindness package that includes a (relatively) flat entry for only. ${ }^{28}$

$\diamond \phi_{\text {only }}$, which, given the flat entry for only, entails that $\diamond \phi$. But this in turn entails that the $\diamond \phi$-alternative to the prejacent is again not excludable. To be sure, matrix $E x h^{p}$ is in some cases very important. For example, (i) arguably implies that Sue believes that John passed:

(i) Sue doubts that only John passed.

On the blindness account, embedded exhaustification of the bare only doesn't predict that. In this case matrix $E x h^{p}$ is crucial. Suppose matrix $E x h^{p}$ associates with only. The prejacent of $E x h^{p}$ is 'Sue doubts that only John passed' and the excludable alternative (obtained via deletion) is 'Sue doubts that John passed'. Given this parse, then, (i) presupposes that it is not the case that Sue doubts that John passed, and asserts that Sue doubts that only John passed. The presupposition may in turn be strengthened via a general or domain-specific ('opinionated speaker'-style) default assumption that if it's not the case that S doubts $\phi$, S believes $\phi$.

28 My aim here is not to settle the semantics of only, an (in)famously thorny issue (see Horn 1996; Ippolito 2007; van Rooij and Schulz 2007; Xiang 2017, a.o.). Even if we accept the revised oddness package, various details of its semantics are negotiable. I have argued that we should not assume that only $\phi$ presupposes $\phi$; but this is compatible with holding that only has other, non-trivial presuppositions. For example, only $\phi$ could presuppose, roughly, that there is at least one $\psi \in \operatorname{Alt}(\phi)$ such that $\phi \nsubseteq \psi$ and $\psi$ has a reasonable chance of holding, given the information in the common ground (thanks to Eric Swanson for this suggestion). The at-issue content of only $\phi$, on this view, is that $\phi$ holds and that each excludable $\psi \in A l t(\phi)$ is false, despite a prior/common ground-based expectation that at least one has a serious chance of being true. This refinement of the semantics of only issues in good predictions for certain simple variations of our basic oddness pattern, and in addition does not negatively affect our original account of standard Magri-style oddness cases. Consider the contrast in (i):

$C:$ normal (adult) background information

a. Only some lions are mammals.

b. \#Only some lions are robots.

Sentence (ia) is part of our original oddness pattern: the basic observation, recall, is that a conspiracy theorist aware of normal background information can use the only-claim in (ia) to propose radical belief revision, relative to the common ground. However - and this is the interesting observation here - the related version in (ib) sounds odd, although one could argue that given a non-presuppositional only it should also be usable for a similar purpose, under 


\section{Independent accounts of oddness? Constraints on 'good' questions and answers}

The main goal of this paper is to present a revised account of Magri-style oddness that appeals to the existence of implicatures which mismatch with the common ground. Yet the motivation for the innovations proposed here depends, ultimately, on whether we really need an account of oddness based on such mismatching implicatures. In this section, I discuss an independent account of oddness, proposed by Katzir and Singh (2015), which some readers might find attractive. Katzir and Singh argue that Magri-style oddness patterns can be explained via an 'independently justified' discourse condition which says, roughly, that an acceptable/nonodd assertion is one that provides a 'good answer' to a 'good question'. These constraints on questions and answers do cover examples not covered by the revised blindness package. Still, I will argue that, given their most plausible formulation, they can't explain the full oddness pattern. What I propose, instead, is that such question-and-answer constraints should be taken as complementing, rather than competing with, the blindness package. ${ }^{29}$

The proposed constraint on good questions can be formulated as follows:

Question Condition. An assertion $S$ must be 'congruent' to some 'good question' $Q$, where:

(i) $S$ is 'congruent' to $Q$ if it provides at least a partial answer to $Q$.

similar conditions. The explanation for the oddness of (ib), according to our refined entry for only, is based on presupposition failure. (ia) presupposes that the proposition that all lions are mammals is a serious possibility, given the information in $C$ (and asserts that it happens to be false). This presupposition is trivially entailed by normal adult background information. In contrast, (ib) presupposes that the proposition that all lions are robots is a serious possibility, given the information in $C$ (and asserts that it happens to be false). Crucially, this presupposition is not entailed by normal background information, and is even inconsistent with it (recall: presuppositions that are inconsistent with the common ground are hard to globally accommodate). This presupposition failure explains the oddness of (ib). Finally, this refined entry for only does not negatively affect our previous account of the more complicated examples included in the full oddness pattern. Consider:

(ii) $\quad$ : normal (adult) background information

a. \#Some Italians come from a beautiful country.

b. Only some Italians come from a beautiful country.

The challenge, recall, is to come up with an account of covert exhaustification and only that can explain why only (iib) is a felicitous and suitable way to call for revision of the common ground. According to our revised entry for only, (iib) presupposes that the proposition that all Italians come from a beautiful country is a reasonable possibility, given the common ground $C$ (and asserts that, despite this reasonable expectation, some but not all do). This presupposition is either entailed by the common ground, or can at least be easily accommodated. As a result, (iib) is correctly predicted to be felicitous, even if most interlocutors with normal background information would also hold that it is obviously false.

29 Katzir and Singh (2015) is not the only recent attempt to deal with Magri-style oddness patterns without adopting the hypothesis that covert exhaustification is contextually blind and obligatory. I decided to discuss Katzir and Singh's 2015 account here mainly because it is prima facie promising and independently motivated. Other important accounts are presented in Schlenker (2012) and Spector (2014). For a critical discussion of the latter, and further defense of the revised blindness package relative to various recent neo-Gricean alternatives, see Del Pinal (2020). 
(ii) $Q$ is a 'good question' at point $t$ in a conversation if it is common ground at $t$ that all participants in the conversation are interested in settling $Q$.

The precise details of the Question Condition are negotiable. Still, some version of this constraint is independently plausible (cf. Roberts 2012; Beaver et al. 2017). For example, the Question Condition arguably helps explain the oddness of examples like (76a) and (76b), which, as Spector (2014) points out, is not predicted or covered by common ground-mismatching implicatures (since there aren't any mismatching implicatures in these cases):

(76) $C$ : Marriage is monogamous; people either don't wear gloves or wear gloves on both hands.

a. \#Sue has one husband.

b. \#Mary put on two gloves.

According to this account, explicitly mentioning an otherwise settled question can improve the target expressions, arguably because we can sometimes revise the common ground to admit such explicit questions. This prediction seems to be correct:

(77) a. How many husbands does Sue have?

b. Sue has one husband.

(78) a. How many gloves did Mary put on?

b. Mary put on two gloves.

However, the Question Condition, on its own, can't explain the full oddness pattern. To begin to see why, consider again (76a) and (76b). Out of the blue, perhaps the most salient question that $(76 \mathrm{a})$ could be addressing is the deficient one in (77a). Similarly, (76b) might be taken as addressing the deficient question in (78a). ${ }^{30}$ Still, we could also accommodate (76a) as an answer to (79a), and (76b) as an answer to (80a):

(79) a. Does Sue have a husband?

b. Sue has one husband.

a. Did Mary put on gloves?

b. Mary put on two gloves.

In this case, (76a) and (76b) provide relevant answers, i.e., informative ones even if a bit long, given a 'normal' common ground like (76). Accordingly, the Question Condition, on its own, doesn't predict oddness for (76a) and (76b) over that predicted, in matching context (e.g., out of the blue), for Sue has a husband and Mary put on gloves. At this point, it is easy to see why our target oddness pattern is not handled by the Question Condition. Consider again one of our main examples:

\footnotetext{
30 By 'deficient question' here I mean relative to 'normal' background information such as that in (76). How do we square the observation that, out of the blue, (76a) and (76b) are odd because they are taken as addressing such 'deficient questions' with the claim that explicitly mentioning these questions improves their acceptability? Arguably, interlocutors are more willing to perform the required costly accommodation of such deficient questions when they are explicitly raised.
} 
(81) Ad hoc $C$ : In this department, every year every professor gives the same grade to all of her students. Jasmine is a professor in this department.

a. \#This year, Jasmine gave an A to some of her students.

b. This year, Jasmine gave an A to all her students.

The challenge is that both (81a) and (81b) could address the following good question: 'What grade did Jasmine assign to her students?' Crucially, not only do (81a) and $(81 \mathrm{~b})$ provide an answer to a relevant question; in addition, and due to the content of the ad hoc common ground, they provide an answer that is equally informative.

To address this problem, Katzir and Singh (2015) suggest that the Question Condition should be paired with a constraint on good answers. Some details are again negotiable, but their basic proposal can be formulated as follows:
a. Answer Condition. A good answer $\phi$ to a question $Q$ is a true answer that is relevant to $Q$, and there is no other true $\psi$ relevant to $Q$ s.t. $\psi \prec \phi(\approx$ ' $\psi$ is a 'better linguistic object' than $\phi ')$.
b. $\quad \psi \prec \phi:=\psi \preceq \phi \wedge \phi \npreceq \psi$
c. $\psi \preceq \phi:=\psi \leqslant \phi \wedge \psi \subseteq \phi$
d. ' $\psi \leqslant \phi$ ' says that $\psi$ is at least as structurally simple as $\phi$. ' $\psi \subseteq \phi$ ' says that $\psi$ entails $\phi$.

Let us see how the Answer Condition complements the Question Condition to capture the contrast between (81a) and (81b). Suppose again that $Q$ is 'What grade did Jasmine assign to her students?' (81a) and (81b) have equal structural complexity. However, $\llbracket(81 \mathrm{a}) \rrbracket \nsubseteq \llbracket(81 \mathrm{~b}) \rrbracket$, whereas $\llbracket(81 \mathrm{~b}) \rrbracket \subseteq \llbracket(81 \mathrm{a}) \rrbracket$. It follows that only (81b) provides a good answer to $Q$. The Answer Condition, then, is a crucial component of this account.

As Katzir and Singh (2015, p. 313) point out, '[the Question and Answer conditions] are conditions on appropriate speech acts. Thus, they must apply globally.' This raises both conceptual and empirical problems. As captured in (82c), the Answer Condition - just like blind $E x h^{p}$ — uses a notion of entailment that is strictly logical, and in particular blind to the common ground. This feature of the Answer Condition is non-negotiable insofar as this condition is intended to cover patterns like (81a)-(81b). For suppose, instead, that we use a notion of entailment given the common ground, by replacing, in the formulation of the Answer Condition, (82c) with (83):

$$
\psi \preceq \phi:=\psi \leqslant \phi \wedge \psi \cap C \subseteq \phi
$$

It then follows, given the context in (81), that $\llbracket(81 \mathrm{a}) \rrbracket \cap C=\llbracket(81 \mathrm{~b}) \rrbracket \cap C$. And since (81a) and (81b) have equal structural complexity, (81b) would not, given this nonblind Answer Condition, be a better answer than (81a). As a result, we no longer predict the contrast in (81a)-(81b). But if we conceive of the Answer Condition as a global condition on speech acts, why should it be formulated in terms of a contextually blind notion of entailment? Indeed, a purely logical constraint which can be taken as a natural characteristic of specific linguistic operators may amount to an ad hoc stipulation when used to specify felicity conditions on speech acts.

The global nature of the Answer Condition also prevents it from explaining our full oddness pattern. This is because most of our key examples can be reformulated 
as cases of embedded oddness, as emphasized by Magri (2011). Consider (84), an embedded version of the oddness pattern in (81):

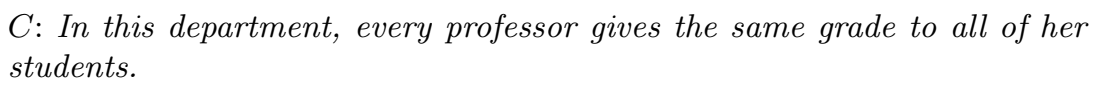

a. \#This year, every professor who assigned an A to some of her students got a prize from the Dean.

b. This year, every professor who assigned an A to all of her students got a prize from the Dean.

Suppose we drop the oddness package and assume that there isn't an embedded $E x h^{p}$ in the restrictor of the universal quantifier. It follows that $\llbracket(84 a) \rrbracket \subseteq \llbracket(84 b) \rrbracket$. Since (84a) and (84b) are of equal structural complexity, (84a) is as good an answer as (84b). So the Answer Condition, on its own, doesn't predict the contrast between cases like (84a) and (84b). In contrast, these embedded patterns can be explained if we adopt the revised blindness package. On this view, (84a) has an LF as in (85):

$E x h^{p}$ [every professor $x\left[E x h^{p}[x\right.$ assigned an A to some of $x$ 's students $][x$ got a prize from the Dean]]]

a. $\quad \operatorname{ACC}\left[E x h^{p}[x\right.$ assigned an A to some of $x$ 's students $\left.]\right] \approx x$ assigned an A to some but not to all of $x$ 's students

b. $E x h^{p}[x$ assigned an A to some of $x$ 's students $] \approx$ $\{$ ps: $\neg x$ assigned an A to all of $x$ 's students at-issue: $x$ assigned an A to some of $x$ 's students

Note that the embedded $E x h^{p}$ generates a 'some but not all' enrichment. To see why, recall that relevance for $E x h^{p}$ is calculated relative to its local context. In the case of this embedded $E x h^{p}$, this is simply the global context. Since the prejacent of the embedded $E x h^{p}$ is contextually equivalent to its $\forall$-alternative, the latter is a relevant and excludable alternative. Accordingly, this embedded $E x h^{p}$ triggers a 'some but not all' enrichment which, given the ad hoc common ground, entailsindependently of whether that enrichment is locally accommodated, as in (85a), or projects, as in (85b) - that the restrictor of the universal quantifier is empty, thereby explaining the oddness of (84a).

These conceptual and empirical shortcomings of the Answer Condition are neutralized if we take it as a genuine pragmatic constraint that, instead of competing with the revised blindness package for descriptive coverage, works with it as part of a general account of oddness. From this perspective, the Answer Condition should be formulated in terms of non-blind contextual entailment, as in (83). This move would nicely complement the predictions and limitations of the blindness package. To see why, note that the Answer Condition, in its blind formulation, doesn't predict the oddness of examples like (76b). The reason is that Mary put on gloves doesn't logically entail that Mary put on two gloves. The former does, however, contextually entail the latter, given normal background knowledge. Accordingly, we get the right prediction if we move to a non-blind version of the Answer Condition - which, again, is a more natural formulation for a global constraint on speech acts. This is a welcome result for the blindness package: for as we said above, examples like (76b) cannot be explained via enriched readings which are inconsistent with the common ground. Again, although a non-blind ver- 
sion of the Answer Condition won't cover our basic oddness patterns, including (81a)-(81b), this is not a problem if we take the revised blindness package and the Question and Answer Conditions as complementary accounts. ${ }^{31}$

\section{Conclusion}

As Magri (2009, 2011, 2017) emphasizes, to understand how scalar implicatures are computed, we need to examine not only cases in which enriched readings increase the informativity or coherence of assertions, but also those in which scalar enrichments seem to misfire and generate oddness. Magri argues persuasively that examples like (4a) and (4b) are instances of the latter phenomenon. A key insight of his work is that the systematic generation of implicatures that result in enriched readings which clash with the common ground is only really expected if we assume that implicatures are computed by an exhaustification operator that is obligatory and that determines which alternatives to excludable on the basis of a purely logical notion of entailment which is blind to non-linguistic information in the common ground. Building on Magri's version of the grammatical approach to scalar implicatures, I presented here a 'revised blindness package' which consists of three core innovations relative to Magri's original account. First, I proposed an oddness filter that is derived as a conservative extension of an independently motivated constraint on accommodation. Second, I proposed a novel formulation of covert exhaustification, $E x h^{p}$, that models it as a presupposition trigger relative to its excluded alternatives. Finally, I dropped the strong presuppositional account of overt exhaustification with only in favor of a flat account in which the prejacent is also part of the assertive content. I argued that these modifications of Magri's blindness package improve its predications vis-à-vis the full oddness pattern: specifically, we can now capture the distinction between assertions that lead to successful calls for revision of the common ground and superficially similar assertions which systematically fail in that function and remain resiliently odd. I defended the independent plausibility of each of these innovations, and argued in particular that $E x h^{p}$ helps solve various problems faced by extant theories of covert and overt exhaustification with only.

Acknowledgements Versions of this paper were presented at the University of Barcelona and the University of Illinois at Urbana-Champaign. Thanks to audiences at those talks. For very helpful comments/conversations, I'm grateful to Itai Bassi, Gennaro Chierchia, Manuel GarcíaCarpintero, Peter Lasersohn, Paul Marty, Josep Macià, Marie-Christine Meyer, Eleonore Neufeld, Jacopo Romoli, Adam Sennet, Brandon Waldon, and Yimei Xiang. I am also indebted to two anonymous reviewers and the editors of Natural Language Semantics for extremely helpful questions, comments, and suggestions, and to Christine Bartels for her amazing copy editing work. I am specially grateful to Uli Sauerland and Eric Swanson for many insightful

\footnotetext{
31 This combination of choices, however, has a cost (which I will leave for now as an open problem). For it arguably leaves us without a satisfactory explanation of embedded oddness for cases like (ia)-(ib). Although I think their contrast in acceptability is clear, we can't appeal to mismatching implicatures or to a global answer condition to explain the oddness of (ib), relative to (ia).
}

(i) a. Every student who put on gloves avoided the cold.

b. \#Every student who put on two gloves avoided the cold. 
conversations on versions of this paper and more generally on the topic of neo-Gricean vs. grammatical approaches to implicatures and exhaustification.

\section{References}

Bassi I, Del Pinal G, Sauerland U (2020) Presuppositional exhaustification, manuscript, MIT, UIUC, ZAS Berlin

Beaver DI, Roberts C, Simmons M, Tonhauser J (2017) Questions under discussion: Where information structure meets projective content. Annual Review of Linguistics 3(19):1-19

Chemla S, Singh R (2014a) Remarks on the experimental turn in the study of scalar implicature, part i. Language and Linguistic Compass 8/9:373-386

Chemla S, Singh R (2014b) Remarks on the experimental turn in the study of scalar implicature, part ii. Language and Linguistic Compass 8/9:387-399

Chierchia G (2004) Scalar implicatures, polarity phenomena, and the syntax/pragmatics interface. In: Belleti A (ed) Structures and Beyond, Oxford University Press, Oxford, UK, pp 39-103

Chierchia G (2013) Logic in grammar: Polarity, free choice, and intervention, vol 2. Oxford University Press, Oxford

Chierchia G, Fox D, Spector B (2012) Scalar implicature as a grammatical phenomenon. In: Maienborn C, von Heusinger K, Portner P (eds) Semantics: An International Handbook of Natural Language Meaning, vol III, Mouton de Gruyter, Berlin, chap 87, pp 2297-2331

Del Pinal G (2020) On the computation of scalar implicatures: oddness, exhaustification, and logical vs. contextual entailment, manuscript, UIUC

Del Pinal G, Bassi I, Sauerland U (2020) Embedded free choice and presuppositional exhaustification, manuscript, UIUC, MIT, ZAS Berlin

Fox D (2007) Free choice and the theory of scalar implicatures. In: Sauerland U, Stateva P (eds) Presupposition and implicature in compositional semantics, Palgrave Macmillan, New York, pp 71-120

Fox D, Katzir R (2011) On the characterization of alternatives. Natural Language Semantics 19,:87-107

Fox D, Spector B (2018) Economy and embedded exhaustification. Natural Language Semantics 26:1-50

Gajewski J, Sharvit Y (2012) In defense of the grammatical approach to local implicatures. Natural language semantics 20(1):31-57

Geurts B (1999) Presuppositions and Pronouns. Elsevier, New York

Geurts B, van der Sandt (2004) Interpreting focus. Theoretical Linguistics 30:1-44

Gotzner N, Benz A (2018) The best response paradigm: A new approach to test implicatures of complex sentences. Frontiers in Communication 2(21):1-13, DOI 10.3389/fcomm.2017.00021

Grice P (1975) Logic and conversation. In: Cole P, Morgan JL (eds) Syntax and Semantics, vol 3, Academic Press, New York, pp 41-58

Grice P (1989) Studies in the way of words. Harvard University Press, Cambridge, MA

Heim I (1983) On the projection problem for presuppositions. In: Barlow M, Flickinger D, Wescoat M (eds) WCCFL 2: Second Annual West Coast Conference on Formal Linguistics, pp 114-125 
Heim I (1992) Presupposition projection and the semantics of attitude verbs. Journal of Semantics 9:183-221

Horn L (1969) A presuppositional analysis of 'only' and 'even'. In: Papers from the Fifth Regional Meeting of the Chicago Linguistics Society, CLS, Chicago, IL, pp 98-102

Horn L (1989) A Natural History of Negation. University of Chicago Press, Chicago, IL

Horn L (1996) Exclusive company: 'Only' and the dynamics of vertical inference. Journal of Semantics 13:1-40

Horn L (2006) The border wars: A neo-Gricean perspective. In: von Heusinger K, Turner K (eds) Where semantics meets pragmatics, Elsevier, New York

Ippolito M (2007) On the meaning of only. Journal of Semantics 25:45-91, DOI $10.1093 / \mathrm{jos} / \mathrm{ffm} 010$

Katzir R, Singh R (2015) Economy of structure and information: Oddness, questions, and answers. In: Csipak E, Zeijlstra H (eds) Proceedings of Sinn und Bedeutung, Gottingen, vol 19, pp 302-319

Lewis D (1979) Scorekeeping in a language game. Journal of Philosophical Logic 8:339-359

Magri G (2009) A theory of individual-level predicates based on blind mandatory scalar implicatures. Natural language semantics 17(3):245-297, DOI 10.1007/ s11050-009-9042-x

Magri G (2011) Another argument for embedded scalar implicatures based on oddness in downward entailing environments. Semantics and Pragmatics 4(6):151, DOI $10.3765 / \mathrm{sp} .4 .6$

Magri G (2014) Two puzzles raised by oddness in conjunction. Journal of Semantics $33(1): 1-17$

Magri G (2017) Blindness, short-sightedness, and Hirschberg's contextually ordered alternatives: a reply to Schlenker (2012). In: Pistoia Reda S, Domaneschi F (eds) Linguistic and Psycholinguistic Approaches on Implicatures and Presuppositions, Palgrave Macmillan, Cham, Switzerland, pp 9-54, DOI https: //doi.org/10.1007/978-3-319-50696-8

Marty P, Romoli J (2020) Presupposed free choice and the theory of scalar implicatures. Linguistics \& Philosophy forthcoming

Mayr C, Romoli J (2016) A puzzle for theories about redundancy: Exhaustification, incrementality, and the notion of local context. Semantics and Pragmatics $9(7): 1-48$, DOI $10.3765 / \mathrm{sp}$

Meyer MC (2016) Intonation and local weakening implicatures, talk given at Sinn und Bedeutung 21, University of Edinburgh, September

Pistoia-Reda S (2017) Contextual blindness in implicature computation. Natural Language Semantics 25(2):109-124

Pistoia-Reda S, Romoli J (2017) Oddness and conjunction. In: Pistoia-Reda S, Domaneschi F (eds) Linguistic and Psycholinguistic Approaches on Implicatures and Presuppositions, Springer, Cham, Switzerland, pp 55-71

Potts C, Lassiter D, Levy D, Frank MC (2016) Embedded implicatures as pragmatic inferences under compositional lexical uncertainty. Journal of Semantics 33:755-802, DOI 10.1093/jos/ffv012

Roberts C (2011) only: A case study in projective meaning. The Baltic International Yearbook of Cognition, Logic and Communication 6:1-59, DOI https://doi.org/10.4148/biyclc.v6i0.1581 
Roberts C (2012) Information structure in discourse: towards an integrated formal theory of pragmatics. Semantics and Pragmatics 5:1-69

Romoli J (2011) The presuppositions of soft triggers aren't presuppositions. In: Proceedings of SALT 21, LSA, Rutgers University, vol 21, pp 236-256, DOI http://dx.doi.org/10.3765/salt.v21i0.2619

Romoli J (2015) The presuppositions of soft triggers are obligatory scalar implicatures. Journal of Semantics 32(2):173-219

Rooth M (1992) A theory of focus interpretation. Natural Language Semantics 1(1):75-116

Sauerland U (2004) Scalar implicatures in complex sentences. Linguistics and Philosophy 27(3):397-391

Schlenker P (2012) Maximize presupposition and gricean reasoning. Natural Language Semantics 20(4):391-429

Simons M, Tonhauser J, Beaver D, Roberts C (2010) What projects and why. In: Li N, Lutz D (eds) Proceedings of SALT 20, Linguistic Society of America, pp 309-327, DOI 10.3765/salt.v20i0.2584

Spector B (2014) Scalar implicatures, blindness and common knowledge: comments on Magri (2011). In: Pistoia Reda S (ed) Semantics, Pragmatics and the Case of Scalar Implicatures, Palgrave-Macmillan, Cham, Switzerland, pp 146-169

Spector B, Sudo Y (2017) Presupposed ignorance and exhaustification: how scalar implicatures and presuppositions interact. Linguistics and Philosophy 40:473517

Stalnaker R (1978) Assertion. In: Cole P (ed) Pragmatics, Academic Press, New York, pp 315-332

Stalnaker R (1998) On the representation of context. Journal of Logic, Language and Information 7:3-19

Stalnaker R (2014) Context. Oxford University Press, Oxford, UK

Sudo Y (2018) Its not always redundant to assert what can be presupposed, manuscript, UCL

van Rooij R, Schulz K (2007) Only: Meaning and implicatures. In: Aloni M, Butler A, Dekker P (eds) Questions in Dynamic Semantics, vol 17, Brill, Leiden, Netherlands, chap 9, pp 193-223, DOI 10.1163/9780080470993_010

von Fintel K (2008) What is presupposition accommodation, again? Philosophical Perspectives 22:137-170

Xiang Y (2017) Only: An NPI-licenser and NPI-unlicenser. Journal of Semantics 34:447-481, DOI https://doi.org/10.1093/jos/ffx006 